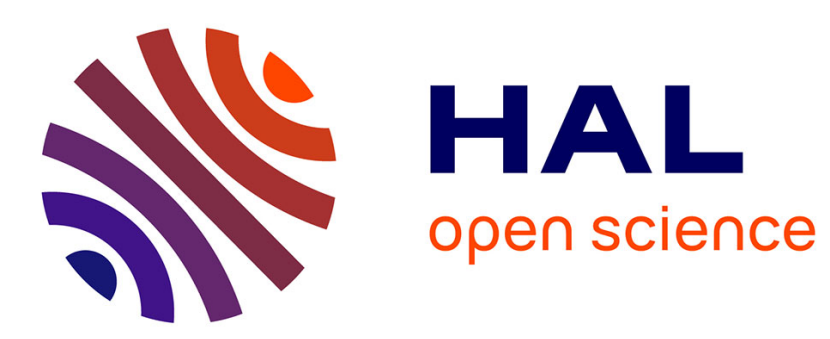

\title{
Multicomponent Solubility of Vapors in Polyethylene: An Experimental and Theoretical Analysis
}

Amel Ben Mrad, Sebastien Norsic, Nida Sheibat-Othman, Timothy Mckenna

\section{To cite this version:}

Amel Ben Mrad, Sebastien Norsic, Nida Sheibat-Othman, Timothy Mckenna. Multicomponent Solubility of Vapors in Polyethylene: An Experimental and Theoretical Analysis. Industrial and engineering chemistry research, 2021, 60 (29), pp.10791-10806. 10.1021/acs.iecr.1c00207 . hal-03312471

\section{HAL Id: hal-03312471 \\ https://hal.science/hal-03312471}

Submitted on 5 Oct 2021

HAL is a multi-disciplinary open access archive for the deposit and dissemination of scientific research documents, whether they are published or not. The documents may come from teaching and research institutions in France or abroad, or from public or private research centers.
L'archive ouverte pluridisciplinaire HAL, est destinée au dépôt et à la diffusion de documents scientifiques de niveau recherche, publiés ou non, émanant des établissements d'enseignement et de recherche français ou étrangers, des laboratoires publics ou privés. 


\title{
A Novel Approach for the Estimation of the Sanchez-Lacombe Interaction Parameters for the Solubility of Ternary Polyolefins
}

\section{Systems}

$\underline{\text { Amel Ben Mrad }}^{\mathrm{a}}$, Nida Sheibat-Othman ${ }^{\mathrm{b}}$, Jorik Hill $^{\mathrm{c}}$, Michael Bartke ${ }^{\mathrm{c}}$, Timothy F. L. McKenna ${ }^{\mathrm{a}, *}$

${ }^{a}$ C2P2 (LCPP), UCBL/CNRS-CPE, UMR 5265, Villeurbanne, France

${ }^{\mathrm{b}}$ University of Lyon, University Claude Bernard Lyon 1, CNRS, LAGEPP UMR 5007, F-69100 Villeurbanne, France

${ }^{\mathrm{c}}$ Martin-Luther-University Halle-Wittenberg, Heinrich-Damerow-Straße 4, 06120 Halle, Germany

\section{Highlights}

- Experimental method for evaluating the individual solubilities in a mixture of two gases based only on total solubility measurements.

- Modeling ternary systems with Sanchez-Lacombe Equation of State

- Implementing Peng-Robinson EoS to fit global solubility with Sanchez-Lacombe EoS

- Demonstration of co- and anti-solubility effects of heavy and light components respectively.

\begin{abstract}
Total solubility data was collected for mixtures of alkanes and/or alkenes in polyethylene. These measurements were combined with the independent estimate of the compressibility
\end{abstract}


factor for a mixture of gases as a second "data source" to fit the interaction parameters in the Sanchez-Lacombe equation of state (SL EoS). This makes it possible to calculate individual component solubility data for the two penetrants in non-ideal ternary system where the third phase is polyethylene.

Key words: Sanchez-Lacombe, modeling, ternary system, Peng-Robinson, ICA, co-solubility *E-mail address: timothy.mckenna@univ-lyon1.fr (T.F.L. McKenna) 


\section{Introduction}

Polyethylene (PE) is the most widely produced polymer on the planet because of its extensive range of properties and end-uses, low production cost, and relatively low environmental impact. Polyethylene can be made in solution, slurry and gas phase processes using ethylene, and very often an $\alpha$-olefin comonomer. Gas phase processes are of particular interest as they are used for the production of approximately $75 \%$ of the linear low-density polyethylene (LLDPE), and $25 \%$ of high-density polyethylene (HDPE) worldwide. These processes will be the focus of the current work.

In industrial gas-phase reactors, polyethylene is produced using a catalyst particle that is exposed to a mixture of reactive species that include ethylene, hydrogen, and usually different amounts of an $\alpha$-olefin comonomer such as 1-butene or 1-hexene ${ }^{1}$. As the ratio of ethylene to comonomer is used to control important physical properties such as the density, it is important to be able to predict accurately the concentration of the monomers at the active sites of the catalysts. In addition, inert compounds, typically alkanes as propane, isobutane, isopentane or n-hexane, often referred to as induced condensing agents (ICA), are used to regulate partial pressures and to improve heat transfer ${ }^{2-5}$. All of the species present in the gas phase, inert or not, will diffuse into the amorphous phase of the polymer, and will change the physical and possibly the chemical structure of the final polymer, which in turn can influence important parameters such as individual species solubility and diffusivity ${ }^{6-8}$. It is therefore quite important to know the solubility of the individual species in gas mixtures in the polymer with precision.

As has been discussed elsewhere ${ }^{2,9,10}$, the sorption of ethylene, comonomers and alkanes (used as induced condensing agents, ICA, for instance) is non-ideal. In other words the 
solubility of a mixture of gases in amorphous PE is not the same as the sum of the solubilities of the pure species. Over the last decade, different experimental methods have been developed to measure the solubility of gas solubility in polymers. However, most of these experimental solubility studies are restricted to binary systems (penetrant - PE), with a limited number looking at ternary systems (penetrant $1-$ penetrant $2-\mathrm{PE})^{11-20}$. These studies showed that the solubility of a given component in a polymer is function of the structure of the penetrant, the temperature, pressure and the polymer density and crystallinity. In the case of ternary systems, the composition of the gas-phase has been shown to be very important ${ }^{21}$. For instance, Yao et al. ${ }^{11}$ measured ethylene-alkane-PE systems by varying the partial pressure of n-hexane and iso-pentane as alkanes. They showed that the solubility of ethylene in ternary systems is higher than its solubility in binary systems. Other authors showed the same effect in the presence of co-monomers in ternary systems ${ }^{13,22,23}$. Chmelar et al. ${ }^{14}$ showed that the sorption of 1-hexene increases ethylene solubility in PE. This phenomenon is often referred to as the cosolubility effect. These same authors also demonstrated that increasing ethylene pressures can lead to a decrease in the solubility of 1-hexene at constant 1-hexene pressure (anti-solvent effect). Furthermore, a recent series of articles from our research group has shown that adding ICA to a gas phase polymerization will increase the reaction rate due to the co-solubility effect ${ }^{7,24}$. Alizadeh et al. showed that adding 2.5 bars of n-pentane to 7 bars of ethylene leads to an increase in the initial polymerization rate by a factor 2.5 times with respect to that observed for 7 bars of ethylene alone. The same tendency is seen for $n$-hexane, where they showed that adding 0.8 bars of n-hexane leads to an increase of the initial activity of 1.8 times higher than with ethylene alone. These observed increases in the polymerization rate were attributed in large part to the cosolubility effect, but also to an increase in the diffusivity of ethylene through the amorphous fraction of the polymer ${ }^{6-8}$. 
All these studies show the importance of accounting for the overall composition of the gas phase, since the solubility of monomer and comonomer will be directly impacted by the relative amounts of the different species present in the mixture. Obviously, this means that if one needs to develop models to quantify these effects, appropriate thermodynamic models that can account for these phenomena are needed. It is clear that one cannot use binary sorption models to estimate the concentration of a given species in the polymer for multicomponent systems and simply add them to describe penetrant concentration in the system in order to predict their solubilities. It is necessary to account for the way that they interact with the polymer in a ternary system.

This is of course possible using equations of state. The Sanchez-Lacombe equation of state (SL EoS) and the Perturbated Chain Statistical Associating Fluid Theory (PC SAFT) are two such models that are widely used in the field of polymer reaction engineering. In the PCSAFT model, the molecules are assumed to be constituted of spherical segments of fixed diameter, freely joined. Detailed information about this equation of state can be found elsewhere ${ }^{25,26}$. Sanchez-Lacombe is a model based on the lattice theory, meaning that pure components are assumed to be broken into parts and placed into a lattice structure ${ }^{27}$. The main feature of this model is that it introduces vacant lattice sites or holes, and varying the fraction of holes varies the density and the compressibility. Both of these EoS have been used successfully ${ }^{28}$, but we have chosen to use the SL EoS because of its relative simplicity, which can be easily adapted for use in single particle and reactor models ${ }^{10,29}$, and especially can be extended to multicomponent systems (as we will discuss in a future paper). The main drawbacks to both of these approaches are: (1) they require empirical, adjustable parameters that are specific to a given system; and (2) they were developed for purely amorphous 
materials, so when applied to semi-crystalline materials, they cannot be used to predict the impact of the crystalline phase on penetrant solubility in the amorphous phase à priori.

The adjustable parameters in the SL EoS are the interaction parameters between the penetrant molecules and the polymer (if we assume negligible interactions between the small molecule penetrants), that need to be estimated experimentally. To do so, this equation of state has to be fitted to experimental solubility data, and such data is sorely lacking for multicomponent systems under conditions similar to those used in a polymerization process.

Currently, gravimetric experiments based on a magnetic suspension balance (MSB) are perhaps the most widely used technique for this type of solubility measurement because of their relative simplicity and high precision. A large number of studies have used this method to investigate the impact of partial pressures and temperature on the solubility of (mostly) binary and (very occasionally) ternary systems. In terms of alkenes, data is available for 1hexene solubility for different temperatures, pressures and PE crystallinity ${ }^{13,14,16-20}$. A more limited set of data is available for 1-butene ${ }^{16-20}$ and 1-octene ${ }^{18,19}$. In the case of inert ICAs, the solubilities of n-hexane, isopentane, and isobutane have been studied for binary and ternary systems for a large range of temperature and polymer type ${ }^{11,17,20}$, but very limited data can be found for the sorption of propane in PE despite it being an important diluent for a number of processes ${ }^{14}$. Finally, it is not straightforward to measure individual concentrations (and thus individual solubilities) in this type of apparatus, so MSB experiments often give only the total solubilities for a given mixture. The advantage of these experiments is that they are rapid once the device is calibrated, and one can also have access to overall solubility data.

In the present study, the gravimetric technique was used to measure the total solubility of ternary systems that are not available in the literature, such as ethylene/propane/LLDPE, 
ethylene/isobutane/LLDPE and ethylene/1-butene/LLDPE. These systems were measured at $70^{\circ} \mathrm{C}$ and total pressures up to 6 bars. Since individual solubilities are not available with the suspension balance, we used the compressibility factor of the gas mixture calculated with the Peng-Robinson EoS as second data source to estimate the two necessary interaction parameters for the SL EoS. The measured solubilities and compressibility factors were then used to fit the interaction parameters of the Sanchez-Lacombe equation of state. The observed trends were theoretically interpreted because no available data can be found in the literature for these studied systems.

\section{Experimental section}

\subsection{Materials}

Ethylene and argon with minimum purities of 99.5\%, and propylene, butene, butane, and propane with minimum of purities of $99 \%$ were obtained from Air Liquide Germany. Argon was used as blank gas. Linear low-density polyethylene (LLDPE) powders having a crystallinity of $48.3 \%$ were graciously supplied by Borealis.

\subsection{Gravimetric method}

The gravimetric apparatus used to measure the equilibrium solubility data is a magnetic suspension balance (Rubotherm $\mathrm{GmbH}$ ), connected to a pressure cell that contains the polymer sample. The weighing mechanism of the balance is separated from the pressure cell, so it is not exposed to high temperatures and pressures. The apparatus is equipped with temperature and pressure sensors, vacuum pump, heating gas bottles, and recording computer. The data acquired from the gravimetric experiment are pressure, temperature, time and 
sample mass. The magnetic coupling between the balance and the sample in the pressure chamber allows an accuracy of $0.1 \mathrm{mg}$ for weight measurements. The setup is described in more detail in references ${ }^{30-32}$, but we will briefly describe the measuring procedure and the corrections that have to be done.

1-2 grams of polymer particles (powder withdrawn directly from the reactor) are used for each sorption experiment ( $\left.m_{\text {sample }}\right)$. The polymer sample is first degassed under 40 mbar of vacuum for at least 45 minutes at the desired temperature. The process gas mixture is then injected into the pressure cell at the desired pressure and temperature. Pressure steps are then performed in the chamber, and as this pressure is increased, the gas density increases which results in higher buoyancy force acting on the container and the sample. The reading of the balance must be corrected for this buoyancy force. First, a blank run using nitrogen and without polymer sample determines the buoyancy of the sample container. Then, a second run with the polymer sample is performed to estimate the volume of the measured sample required for the buoyancy correction of the sample mass.

$$
m_{\text {corrected }}=m_{\text {balance }}+V_{\text {container+sample }} \rho_{\text {gas }}
$$

Where the volume of the container with the sample has been calculated during the second run. Gas densities of propane, isobutane and 1-butene and their mixture at the temperature and pressure of interest were calculated for each set of experimental condition using the ideal gas law corrected for compressibility calculated with Peng-Robinson EoS.

The mass of the sample with the adsorbed gas is given by the following expression:

$$
m=m_{\text {corrected }}-m_{\text {container }}
$$


Because PE is semicrystalline, it is necessary to evaluate the solubility by taking into account the crystalline phase where the solubility of the penetrants is zero. Thus, the solubility in the amorphous phase of the polymer is expressed as specific mass change of the sample due to the sorption.

$$
S_{\text {am }}=\frac{m-m_{\text {sample }}}{m_{\text {sample }}(1-\chi)}
$$

Where $\chi$ is the crystallinity fraction. Kosek et al. ${ }^{30}$ demonstrated that taking into account the impact of temperature on the crystallinity is an essential step for the solubility measurement. Therefore, the mass fraction of crystalline material in the polymer at the temperature of interest has been estimated at $47.6 \%$ using differential scanning calorimetry (DSC, Metler Toledo).

3. Thermodynamic modeling

\subsection{Model development}

\subsubsection{Sanchez-Lacombe EoS}

The Sanchez-Lacombe EoS is a lattice-fluid model in which pure components are assumed to be broken into parts and placed into a lattice structure. The SL EoS is basically an extension of the classic Flory-Huggins theory. The main advance is that this model introduces vacant lattice sites to account for the compressibility and the density changes. Thus, the system 
volume or density can vary by changing the fraction of holes in the lattice structure ${ }^{27}$. The main equation of state is given by:

$$
\bar{\rho}^{2}+\bar{P}+\bar{T}\left[\ln (1-\bar{\rho})+\left(1-\frac{1}{r}\right) \bar{\rho}\right]=0
$$

where $\bar{T}, \bar{P}, \bar{\rho}$ are the reduced temperature, pressure, volume and density, respectively. $r$ is the number of sites (mers) a molecule occupies in the lattice. These reduced parameters, depending on the characteristic properties, are defined as follows:

$$
\bar{T}=T / T^{*} \quad \bar{P}=P / P^{*} \quad \bar{\rho}=\rho / \rho^{*}=1 / \bar{V}
$$

where $T^{*}, P^{*}$, and $\rho^{*}$ are the scale factors known as the characteristic temperature, pressure, and density respectively, which are used to characterize each pure component in the mixture. $\bar{V}$ is the reduced volume. These characteristic parameters depend on three lattice parameters, describing the thermodynamic properties of a pure components: $\varepsilon^{*}, v^{*}$ and $\mathrm{r}$, where $\varepsilon^{*}$ is the mer-mer interaction energy $\left(\mathrm{J} \mathrm{mol}^{-1}\right)$ and $v^{*}$ the closed-packed molar volume of a mer $\left(\mathrm{m}^{3}\right.$ $\left.\mathrm{mol}^{-1}\right)$

$T^{*}=\varepsilon^{*} / R \quad P^{*}=\varepsilon^{*} / v^{*} \quad \rho^{*}=\frac{M W}{r v^{*}} \quad V^{*}=N\left(r v^{*}\right)$

Where MW is the molecular weight of the component and $R$ is the universal gas constant $\left(\mathrm{J} \mathrm{K}^{-}\right.$ $\left.{ }^{1} \mathrm{~mol}^{-1}\right)$.

The parameters of SL EoS for each pure component are given in Table 1. 
Table 1. Pure component parameters used in SL EoS

\begin{tabular}{|c|c|c|c|c|}
\hline Component & $\mathbf{T}^{*}(\mathbf{K})$ & $P^{*}($ bar $)$ & $\rho^{*}\left(\mathbf{k g} / \mathbf{m}^{3}\right)$ & Reference \\
\hline Ethylene & 283 & 3395 & 680 & 28 \\
\hline Propane & 371 & 3090 & 690 & 27 \\
\hline Isobutane & 398 & 2840 & 720 & 27 \\
\hline 1-butene & 410 & 3350 & 770 & 33 \\
\hline 1-hexene & 450 & 3252 & 814 & 24 \\
\hline Propylene & 345.4 & 3788 & 755 & 31 \\
\hline LLDPE & 667 & 4370 & 900 & 28 \\
\hline Polypropylene & 690.6 & 3007 & 885.6 & 31 \\
\hline
\end{tabular}

When the SL EoS is used for a mixture of components, it is necessary to define combining rules based on the Van der Waals mixing rule for the estimation of mixture properties (i.e. $\left.\varepsilon_{\text {mix }}^{*}, v_{\text {mix }}^{*}, r_{\text {mix }}\right)$ based on the respective values of the pure component values.

The characteristic closed-packed molar volume of a "mer" of the mixture, $v_{\text {mix }}^{*}$ is defined as follow:

$v_{\text {mix }}^{*}=\sum_{i=1}^{N_{\mathrm{c}}} \sum_{j=1}^{N_{\mathrm{c}}} \phi_{i} \phi_{j} v_{i j}^{*}$

where $\mathrm{N}_{\mathrm{c}}$ denotes the number of components in the mixture 
$v_{i j}^{*}=\frac{v_{i i}^{*}+v_{j j}^{*}}{2}\left(1-n_{i j}\right)$

Where $\phi$ is the volume fraction of the $i^{\text {th }}$ and $j^{\text {th }}$ component in the mixture and $n_{i j}$ corrects the possible deviation of $v_{i j}^{*}$ from the arithmetic mean value of $v_{i i}^{*}$ and $v_{j j}^{*}$ of the pure components. In the present study, the value of the interaction parameter $n_{i j}$ is assumed to be equal to zero.

The closed-packed volume fraction of the $i^{\text {th }}$ component at the limit of zero temperature or incompressible state, $\phi_{i}$ is defined as:

$\phi_{i}=\frac{\omega_{i}}{\rho_{i}^{*} v_{i}^{*}} / \sum_{j=1}^{N_{\mathrm{c}}}\left(\frac{\omega_{j}}{\rho_{j}^{*} v_{j}^{*}}\right)$

where $\omega_{i}$ is the mass fraction of the component $i$ in the mixture.

The mixing rule for the characteristic interaction energy for the mixture $\varepsilon_{\mathrm{mix}}^{*}$ is defined as

$\varepsilon_{\text {mix }}^{*}=\frac{1}{v_{\text {mix }}^{*}} \sum_{i=1}^{N_{\mathrm{c}}} \sum_{j=1}^{N_{\mathrm{c}}} \phi_{i} \phi_{j} \varepsilon_{i j}^{*} v_{i j}^{*}$

The cross-energy parameter between mers of component (i) and component $(\mathrm{j}), \varepsilon_{i j}^{*}$ is introduced in order to take into account the interactions between components in mixtures.

$\varepsilon_{i j}^{*}=\left(\varepsilon_{i i}^{*} \varepsilon_{j j}^{*}\right)^{0.5}\left(1-k_{i j}\right)$

in which $\varepsilon_{i i}^{*}$ and $\varepsilon_{j j}^{*}$ are the interation energy between mers of component $i$ and $j$, respectively. $k_{i j}$ is a binary interaction parameter between the $i^{\text {th }}$ and $j^{\text {th }}$ component in the mixture, which is employed as adjustable parameter to fit the model to experimental solubility data.

Finally, the mixing rule for the number of sites (mers) occupied by a molecule of the mixture, $r_{\text {mix }}$, is given by 
$\frac{1}{r_{\text {mix }}}=\sum_{j=1}^{N_{c}} \frac{\phi_{j}}{r_{j}}$

where $r_{j}$ is the number of sites occupied by molecule $\mathrm{j}$ in the lattice.

For calculation of sorption equilibrium for polymer-penetrant system, the chemical potential of the $i^{\text {th }}$ component in a multicomponent system can be expressed as

$$
\begin{aligned}
\mu_{i}= & R T\left[\ln \phi_{i}+\left(1-\frac{\mathrm{r}_{\mathrm{i}}}{r_{\text {mix }}}\right)\right] \\
& +r_{i}\left\{-\bar{\rho}_{\text {mix }}\left[\frac{2}{\mathrm{v}_{\text {mix }}^{*}}\left(\sum_{j=1}^{N_{\mathrm{c}}} \phi_{j} v_{i j}^{*} \varepsilon_{i j}^{*}-\varepsilon_{\text {mix }}^{*} \sum_{j=1}^{N_{\mathrm{c}}} \phi_{j} v_{i j}^{*}\right)+\varepsilon_{\text {mix }}^{*}\right]\right. \\
& +\frac{R T}{\bar{\rho}_{\text {mix }}}\left[\left(1-\bar{\rho}_{\text {mix }}\right) \ln \left(1-\bar{\rho}_{\text {mix }}\right)+\frac{\bar{\rho}_{\text {mix }}}{r_{i}} \ln \bar{\rho}_{\text {mix }}\right] \\
& \left.+\frac{P}{\bar{\rho}_{\text {mix }}}\left(2 \sum_{j=1}^{N_{\mathrm{c}}} \phi_{j} v_{i j}^{*}-v_{\text {mix }}^{*}\right)\right\}
\end{aligned}
$$

We consider that the chemical potential of each component at equilibrium is equal to the chemical potential of the polymer as follows:

$\mu_{i}^{\mathrm{pol}}=\mu_{i}^{\mathrm{gas}} \quad i=1,2 \ldots$

In which $\mu_{i}^{\text {gas }}$ can be the chemical potential of the monomer, the comonomer, or the ICA.

By solving equations (2) and (11) using a nonlinear algebraic equation solver (e.g. in Matlab), for each component in the ternary system, the volume fraction of each sorbed component in the amorphous polymer can be calculated as follows

$$
\omega_{1, \mathrm{am}}=\frac{\rho_{1}^{*} v_{1}^{*} \phi_{1}^{\mathrm{pol}}}{\rho_{1}^{*} v_{1}^{*} \phi_{1}^{\mathrm{pol}}+\rho_{2}^{*} v_{2}^{*} \phi_{2}^{\mathrm{pol}}+\rho_{3}^{*} v_{3}^{*} \phi_{3}^{\mathrm{pol}}}
$$


$\omega_{2, \mathrm{am}}=\left[\left(\frac{\rho_{2}^{*} v_{2}^{*}}{\rho_{1}^{*} v_{1}^{*}}\right)\left(\frac{\phi_{2}^{\mathrm{pol}}}{\phi_{1}^{\mathrm{pol}}}\right)\right] \omega_{1, \mathrm{am}}$

$\omega_{\mathrm{pol}, \mathrm{am}}=1-\omega_{1, \mathrm{am}}-\omega_{2, \mathrm{am}}$

Finally, the solubility of each component at equilibrium, in gram of component per gram of polymer, $\mathrm{S}$, can be calculated as follows

$S_{i j, \mathrm{am}}=\frac{\omega_{i, \mathrm{am}}+\omega_{j, \mathrm{am}}}{\omega_{\mathrm{pol}, \mathrm{am}}}(1-\chi) \quad i, j=1,2$

where $\chi$ is the crystallinity of the polymer.

For more details on the development and the application of SL EoS to ternary systems, readers may refer to Alizadeh et al. ${ }^{29}$

\subsubsection{Peng-Robinson EoS}

The Peng-Robinson (PR) equation of state ${ }^{34}$ for gas mixture is defined as

$$
P=\frac{R T}{v-b_{\mathrm{m}}}-\frac{a_{\mathrm{m}}(T)}{v\left(v+b_{\mathrm{m}}\right)+b_{\mathrm{m}}\left(v-b_{\mathrm{m}}\right)}
$$

Where $v$ is molar volume. The parameter $a_{\mathrm{m}}$ is a measure of the attractive forces between molecules in the mixture and the parameter $b_{\mathrm{m}}$ is the van der Waals co-volume occupied by these molecules in the mixture. These parameters are defined as follow:

$$
\begin{aligned}
& a_{\mathrm{m}}=\sum_{i=1}^{2} \sum_{j=1}^{2} x_{i} x_{j}\left(1-k_{i j}\right) \sqrt{a_{i} a_{j}} \\
& b_{\mathrm{m}}=\sum_{i=1}^{2} x_{i} b_{i}
\end{aligned}
$$

$a$ and $b$ are the respective PR parameters for pure substances. $x$ is the mole fraction of each component in the mixture and $k_{i j}$ is the binary interaction parameter. This interaction parameter is identified using experimental data, but very few experimental data are available 
in the literature. Besides, when available, less than $0.4 \%$ difference can be seen in the compressibility factor when using identified $k_{i j}$ compared to assuming $k_{i j}=0$. Therefore, as for SL model, we will consider for this study that there is no interaction between small molecules, meaning that $k_{i j}=0$.

Applying the first equation at the critical point, we have:

$$
\begin{aligned}
& a_{i}\left(T_{\mathrm{c}, i}\right)=0.45724 \frac{R^{2} T_{\mathrm{c}, i}{ }^{2}}{P_{\mathrm{c}, i}} \\
& b_{i}\left(T_{\mathrm{c}, i}\right)=0.07780 \frac{R T_{\mathrm{c}, i}}{P_{\mathrm{c}, i}}
\end{aligned}
$$

At temperatures other than the critical temperature, we have:

$$
\begin{aligned}
& a_{i}(\mathrm{~T})=a_{i i}\left(T_{c, i}\right) \cdot \alpha_{i}\left(T_{\mathrm{r}, i}, w_{i}\right) \\
& b_{i}(\mathrm{~T})=b_{i}\left(T_{\mathrm{c}, i}\right)
\end{aligned}
$$

A relationship between $\alpha$ and the reduced temperature $T_{r}$ can be made and linearized as follow

$$
\alpha_{i}\left(T_{\mathrm{r}, i}, w_{i}\right)=\left(1+m_{i}\left(1-T_{\mathrm{r}, i}{ }^{1 / 2}\right)\right)^{2}
$$

Since the acentric factors of all studied species are $w \leq 0.49, m_{i}$, which is a constant characteristic of each substance, is defined as follow:

$$
m_{i}=0.37464+1.54226 w_{i}-0.26992 w_{i}^{2}
$$

Equation (16) can be rewritten as:

$$
Z^{3}-(1-B) Z^{2}+\left(A-3 B^{2}-2 B\right) Z-\left(A B-B^{2}-B^{3}\right)=0
$$

Where 


$$
\begin{aligned}
& A=\frac{a P}{R^{2} T^{2}} \\
& B=\frac{b P}{R T} \\
& Z=\frac{P v}{R T}
\end{aligned}
$$

Where $\mathrm{Z}$ is the compressibility factor.

Table 2 indicates the required properties of few components to implement the PR equation.

Table 2. Critical temperature and pressure, acentric factors and molecular weight for selected

\begin{tabular}{|c|c|c|c|c|c|c|c|}
\hline$w(-)$ & 0.089 & 0.153 & 0.183 & 0.191 & 0.28 & 0.144 & 35 \\
\hline$T_{\mathrm{c}}(\mathrm{K})$ & 282.36 & 369.83 & 407.82 & 419.95 & 504.03 & 364.76 & 36 \\
\hline$P_{\mathrm{c}}($ bar $)$ & 50.318 & 42.471 & 36.4 & 40.4 & 31.4 & 46.126 & 36 \\
\hline$M W\left(\right.$ g.mol $\left.{ }^{-1}\right)$ & 28.054 & 44.1 & 58.12 & 56.108 & 84.16 & 42.08 & 35 \\
\hline
\end{tabular}
fluids.

\section{Ethylene Propane Isobutane 1-butene ${ }^{\text {a }}$ 1-hexene Propylene Ref}

${ }^{\text {a }}$ The properties of 1-butene were taken from reference ${ }^{37}$.

The roots function of Matlab is used to solve this polynomial equation. This equation yields one or three roots depending upon the number of phases in the system. In the two-phase 
region, the largest root is for the compressibility factor of the vapor while the smallest positive root corresponds to that of the liquid.

\subsection{Model solution procedure}

We will define our ternary system as one containing ethylene (1), a penetrant (2) which can be a comonomer or an ICA, and a polymer (3). The corresponding interaction parameters in order to solve SL EoS are $k_{12}, k_{13}, k_{23}$ which are the interactions between the monomer and the penetrant, the monomer and the polymer and the penetrant and the polymer, respectively. We consider that there is no interaction between small molecules; in other words, $k_{12}$ is assumed equal to zero. This leaves us two interaction parameters that need to be estimated in order to solve the Sanchez-Lacombe EoS. In order to do that, one needs to fit this model to experimental solubility data that have been measured for this study using a magnetic suspension balance. However, as we have only global solubilities from this apparatus, this measurement leaves us with only one experimental data to identify two interactions parameters.

From equations (3) and (4), we can calculate the compressibility factor as follows:

$$
Z=\frac{P v}{R T}=\frac{\bar{P} \bar{v}}{\bar{T}} r
$$

We can then extend Equation (2) from SL EoS to calculate the compressibility factor ${ }^{38}$ as follows:

$$
Z=-r\left[\frac{1}{\bar{\rho}} \ln (1-\bar{\rho})+\left(1-\frac{1}{r}\right)+\frac{\bar{\rho}}{\bar{T}}\right]
$$


The identification of the two interaction parameters is now possible by fitting two "experimental" data (one solubility, one compressibility) to Sanchez-Lacombe model. Since, no available experimental data can be found for the compressibility factor, it was calculated with another equation of state, for instance Peng-Robinson $\operatorname{EoS}^{34}$. This will be acceptable as input to the estimation procedure as the compressibility factor for the vapor phase does not have interactions with the polymer and we can therefore have confidence that the value is correct. The detailed procedure of the development of SL EoS associated with PR EoS for the identification of $k_{\mathrm{ij}}$ interaction parameters is presented in Figure 1. 


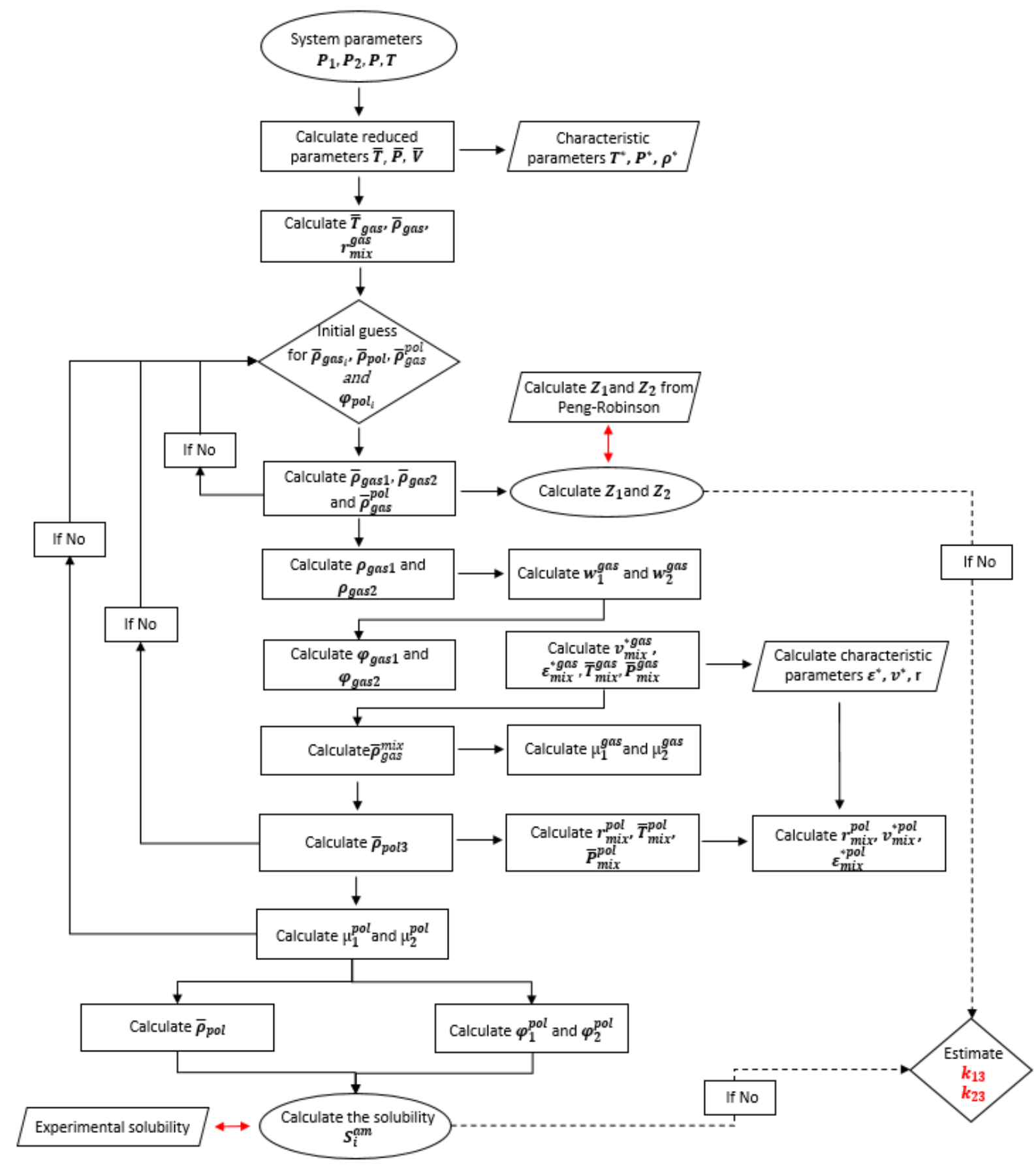

Figure 1. Flowchart for the modeling of ternary systems with SL EoS 


\section{Results and discussion}

In this work, a novel approach consisting of combining the compressibility factor calculated with Peng-Robinson plus experimental global solubility results has been used in order to predict the interactions parameters needed for SL EoS. We will first validate this new approach using previously published experimental data for ternary systems, and then use it to predict the partial solubility of species in ternary systems from the new experimental measurements of the overall solubility using a magnetic suspension balance.

\subsection{Model validation on literature data}

Cancelas et. al. ${ }^{31}$ measured the overall solubility of an equimolar ethylene/propylene mixture in iPP at temperatures above $70^{\circ} \mathrm{C}$ and pressures up to 25 bar, using the same magnetic suspension balance. They used the interaction parameters from the 2 binary systems and readjusted $k_{23}$ at low temperatures to fit the ternary data. In the current study, their experimental overall solubility data for ternary system of ethylene/propylene/iPP coupled with the Peng-Robinson equation were used in order to identify ternary interaction parameters, without using binary interactions parameters. Figure 2 shows the experimental overall solubilities measured by Cancelas et al. ${ }^{31}$ and the corresponding model predictions obtained from SL EoS employing the interaction parameters estimated from overall solubility plus the Peng-Robinson equation (this approach will henceforth be referred to as SL-PR). In Figures Figure 2, Figure 3 and Figure 4, the symbols represent experimental values of the total solubility, and the lines represent the theoretical solubilities calculated with SL-PR method. 


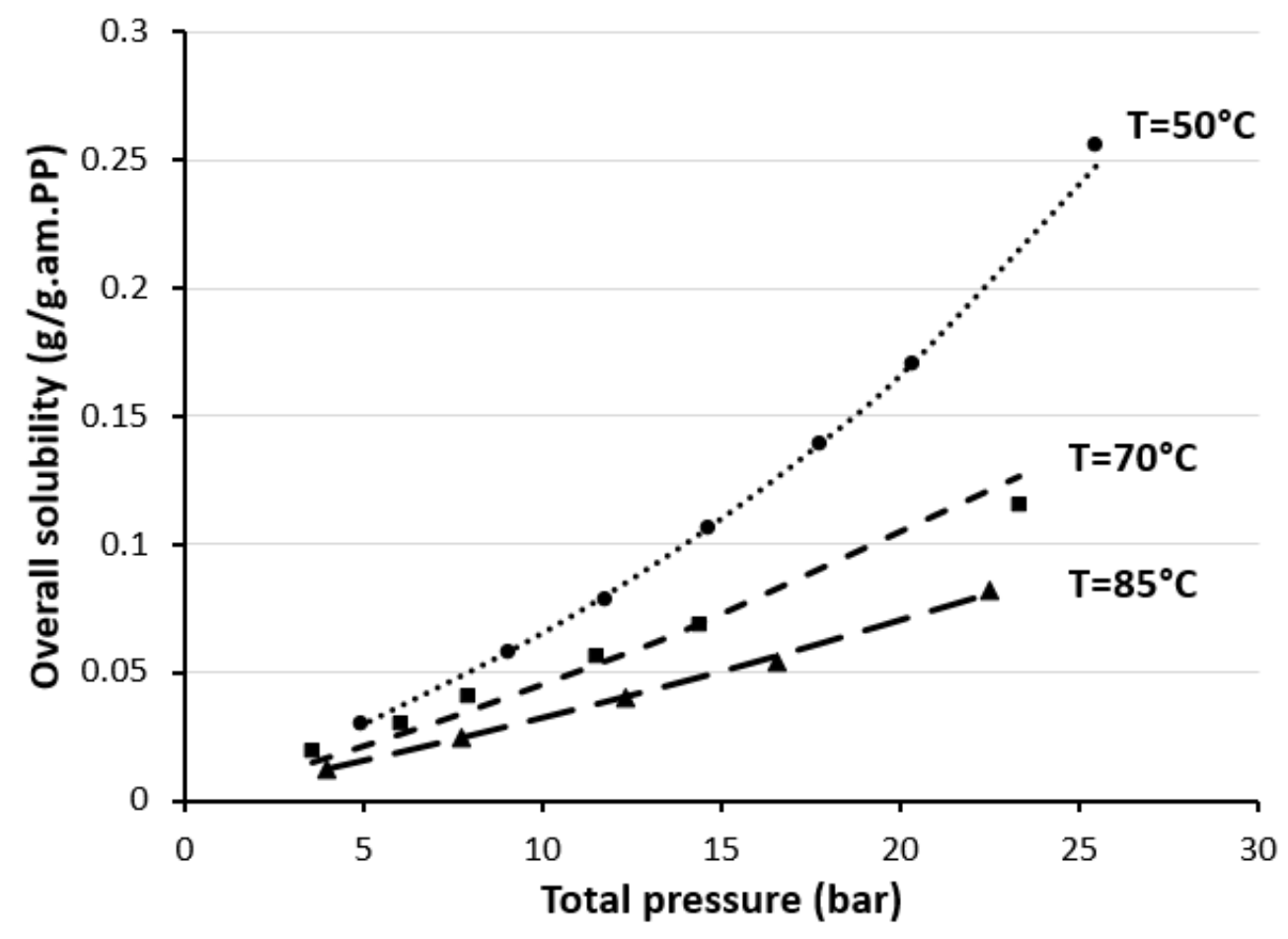

Figure 2. Overall solubilities of an equimolar ethylene/propylene mixture in iPP at 50, 70 and $85^{\circ} \mathrm{C}$. The points are desorption measurements from ${ }^{31}$ and the curves are SL-PR predictions.

A comparison of the ternary interaction parameters of ethylene/propylene mixture in iPP identified in this study and those identified by Cancelas et al. ${ }^{31}$ is given in Table 3. Note that the interaction parameters are temperature-dependent. Indeed, Cancelas et al. identified binary $k_{i j}$ interaction parameters for both binary systems of ethylene/iPP and propylene/iPP by fitting their experimental solubilities as well as solubility data from literature to binary SL EoS. These $k_{i j}$ were then used for ternary system of ethylene/propylene/iPP, but $k_{23}$ had to be readjusted for lower temperatures in order to fit better their experimental ternary global solubility. As can be seen, we find an excellent agreement between the ternary interactions parameters determined with the novel approach SL-PR and the ones determined by Cancelas et al. ${ }^{31}$. However, in the SL-PR method, no re-adjustment of the parameters is required, which makes this novel methodology more robust. Partial solubilities of each component in the 
mixture can then be calculated using SL EoS, as can be seen in Figures Figure 3 and Figure 4. These figures show the solubility of ethylene and propylene in ethylene/propylene/iPP mixture, respectively, at 50, 70 and $85^{\circ} \mathrm{C}$.

Table 3. Comparison of ternary interaction parameters of ethylene/propylene mixture in iPP identified with the novel approach SL-PR by fitting experimental solubilities of Cancelas et al. $^{31}$

\begin{tabular}{lccc}
\hline & $\boldsymbol{T}=50{ }^{\circ} \mathrm{C}$ & $\boldsymbol{T}=70{ }^{\circ} \mathrm{C}$ & $\boldsymbol{T}=85{ }^{\circ} \mathrm{C}$ \\
\hline $\boldsymbol{k}_{\mathbf{1 3}}$ from $^{31}$ & -0.01 & -0.015 & -0.02 \\
$\boldsymbol{k}_{\mathbf{1 3}}$ SL-PR & -0.0095 & -0.0157 & -0.0192 \\
\hline $\boldsymbol{k}_{\mathbf{2 3}}$ from $^{31}$ & 0.01 & 0.005 & -0.005 \\
$\boldsymbol{k}_{\mathbf{2 3}}$ SL-PR & 0.0137 & -0.00026 & -0.00043 \\
\hline
\end{tabular}




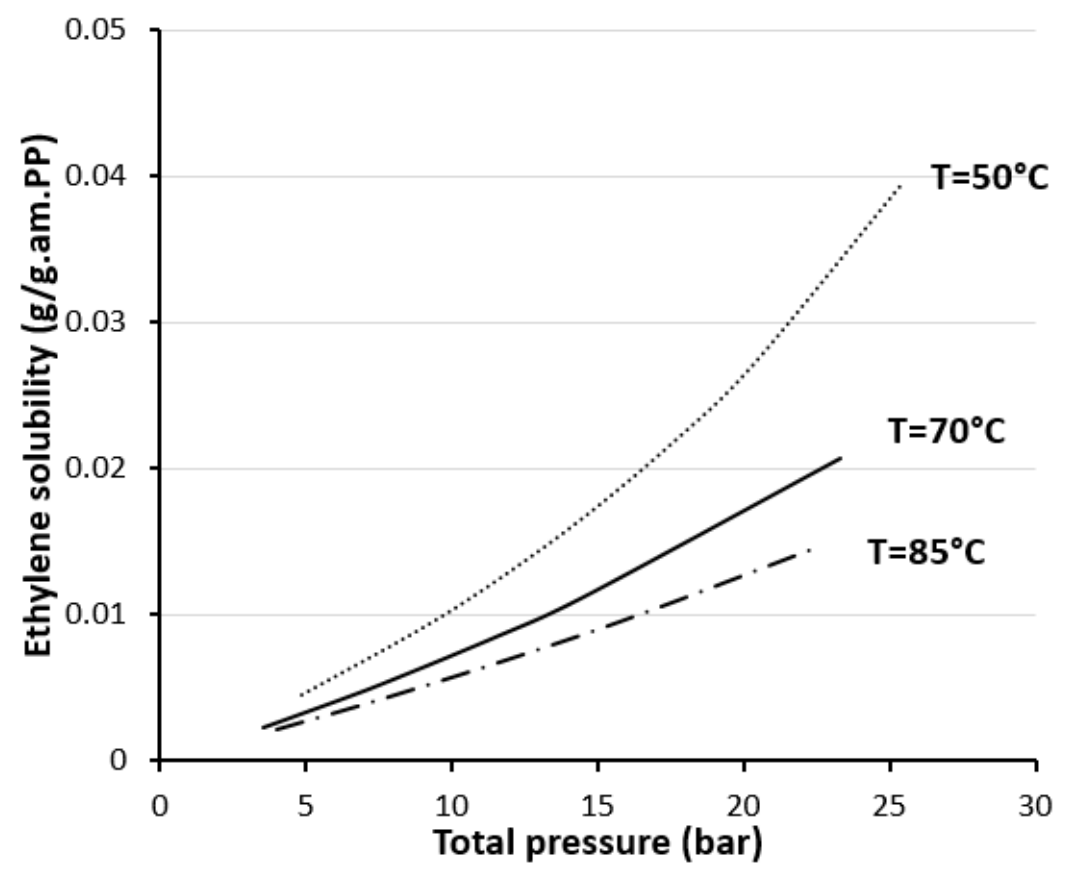

Figure 3. Ethylene partial solubility in an equimolar ethylene/propylene mixture in iP at 50, 70 and $85^{\circ} \mathrm{C}$ from SL. $k_{i j}$ were taken from Table 3.

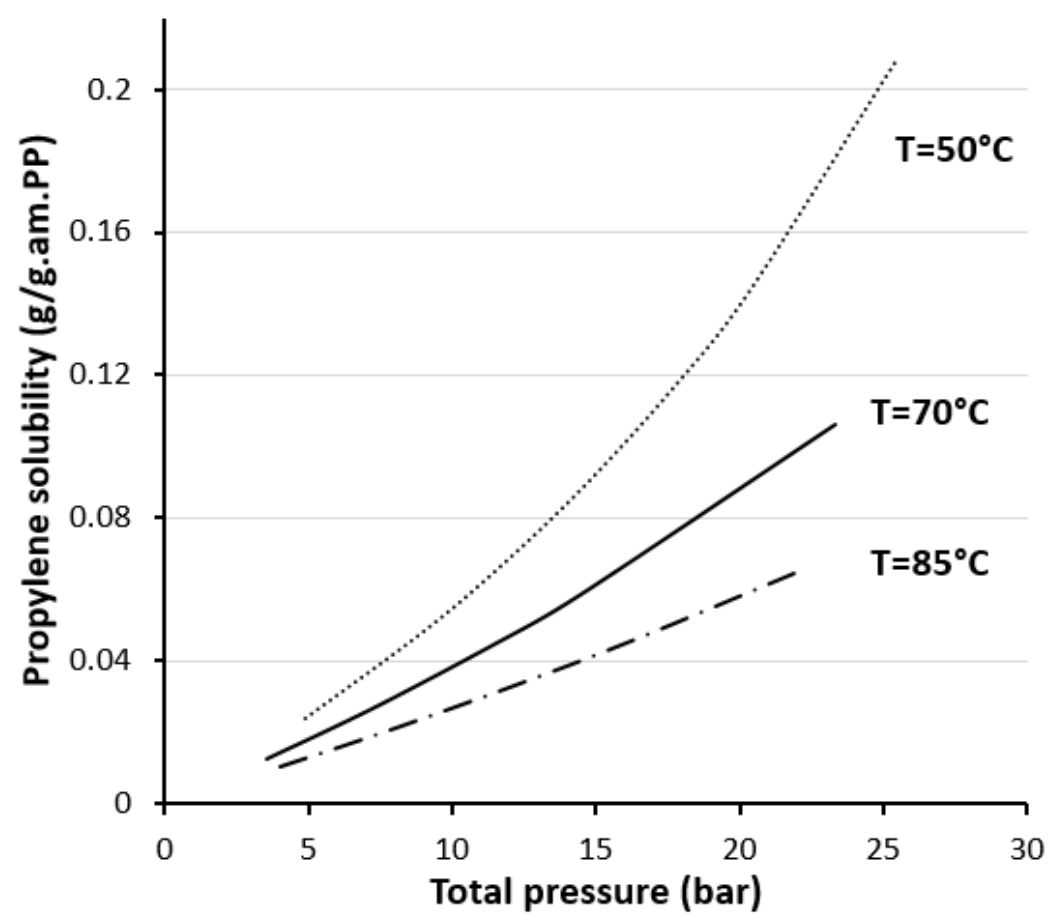

23 
Figure 4. Propylene partial solubility in an equimolar ethylene/propylene mixture in iPP at 50, 70 and $85^{\circ} \mathrm{C}$ from SL. $k_{i j}$ were taken from Table 3.

The second system used to validate this approach is ethylene/1-hexene/LLDPE. Novak et al. ${ }^{13}$ measured ethylene/1-hexene mixture overall solubility in LLDPE-1-hexene copolymer with a constant composition of $4.3 \mathrm{~mol} \%$ 1-hexene and $95.7 \mathrm{~mol} \%$ ethylene at 70,90 and $150^{\circ} \mathrm{C}$. In Figure 5, the overall experimental solubility of ethylene/1-hexene mixture in LLDPE is compared with the corresponding model predictions obtained from SL EoS using the SL-PR method at the different temperatures. In Figure 5 the symbols represent experimental values of the total solubility, and the lines represent the theoretical solubilities calculated with SL-PR method. Ternary interaction parameters were then obtained by fitting SL EoS to the experiments by Novak et al. ${ }^{13}$ at 70,90 and $150^{\circ} \mathrm{C}$ in Table 4 and compared to the interaction parameters obtained by Bashir et al. ${ }^{21}$. These last authors fitted the experimental values of the total solubility found by Novak et al. ${ }^{13}$ with the SL EoS in in a manner similar to how Cancelas et al. ${ }^{31}$ did for the ethylene-propylene-polypropylene system, i.e. they started from the binary interaction parameters identified in binary systems by Novak et al. and re-adjusted these parameters. Partial solubilities of each component in the mixture are then predicted using SL EoS, as can be seen in Figures

\section{Figure 6 and}

Figure 7. These figures show the solubility of ethylene and 1-hexene in ethylene/1hexene/LLDPE mixture, respectively, at 70,90 and $150^{\circ} \mathrm{C}$. 


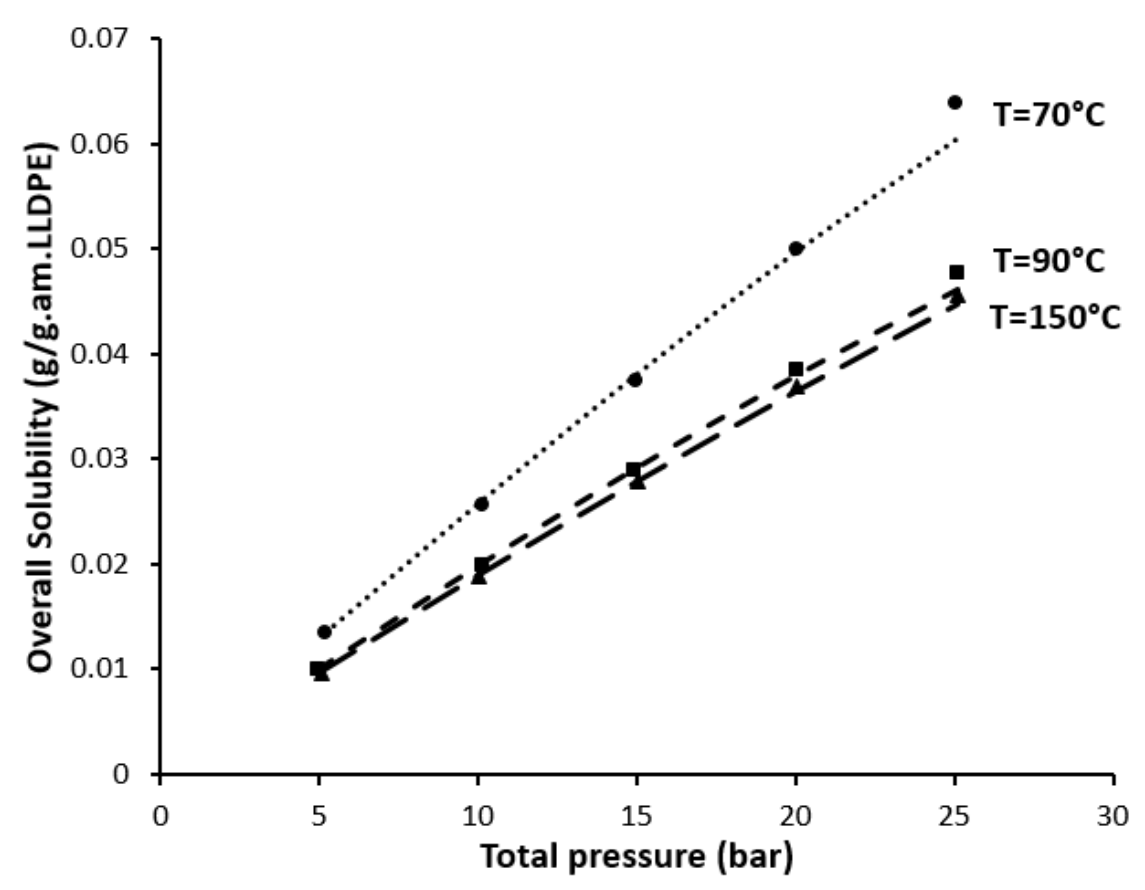

Figure 5. Overall solubilities of an ethylene/1-hexene mixture in LLDPE with 4.3 mol\% 1hexene and $95.7 \mathrm{~mol} \%$ ethylene at 70,90 and $150^{\circ} \mathrm{C}$. The points are sorption measurements from ${ }^{13}$ and the curves are SL-PR predictions.

Table 4. Comparison of ternary interaction parameters of ethylene/1-hexene mixture in LLDPE identified with the novel approach SL-PR by fitting experimental solubilities of Novak et al. ${ }^{13}$ with the interaction parameters found by Bashir et al. ${ }^{21}$

\begin{tabular}{lccc}
\hline & $\boldsymbol{T}=\mathbf{7 0}{ }^{\circ} \mathbf{C}$ & $\boldsymbol{T}=\mathbf{9 0}{ }^{\circ} \mathbf{C}$ & $\boldsymbol{T}=\mathbf{1 5 0}{ }^{\circ} \mathbf{C}$ \\
\hline $\boldsymbol{k}_{\mathbf{1 3}}$ from $^{21}$ & 0.038 & 0.038 & -0.05 \\
$\boldsymbol{k}_{\mathbf{1 3}}$ SL-PR & 0.04188 & 0.0313 & -0.01393 \\
\hline $\boldsymbol{k}_{\mathbf{2 3}}$ from $^{21}$ & 0.027 & 0.016 & -0.03 \\
$\boldsymbol{k}_{\mathbf{2 3}}$ SL-PR & 0.04894 & 0.0403 & -0.03258 \\
\hline
\end{tabular}




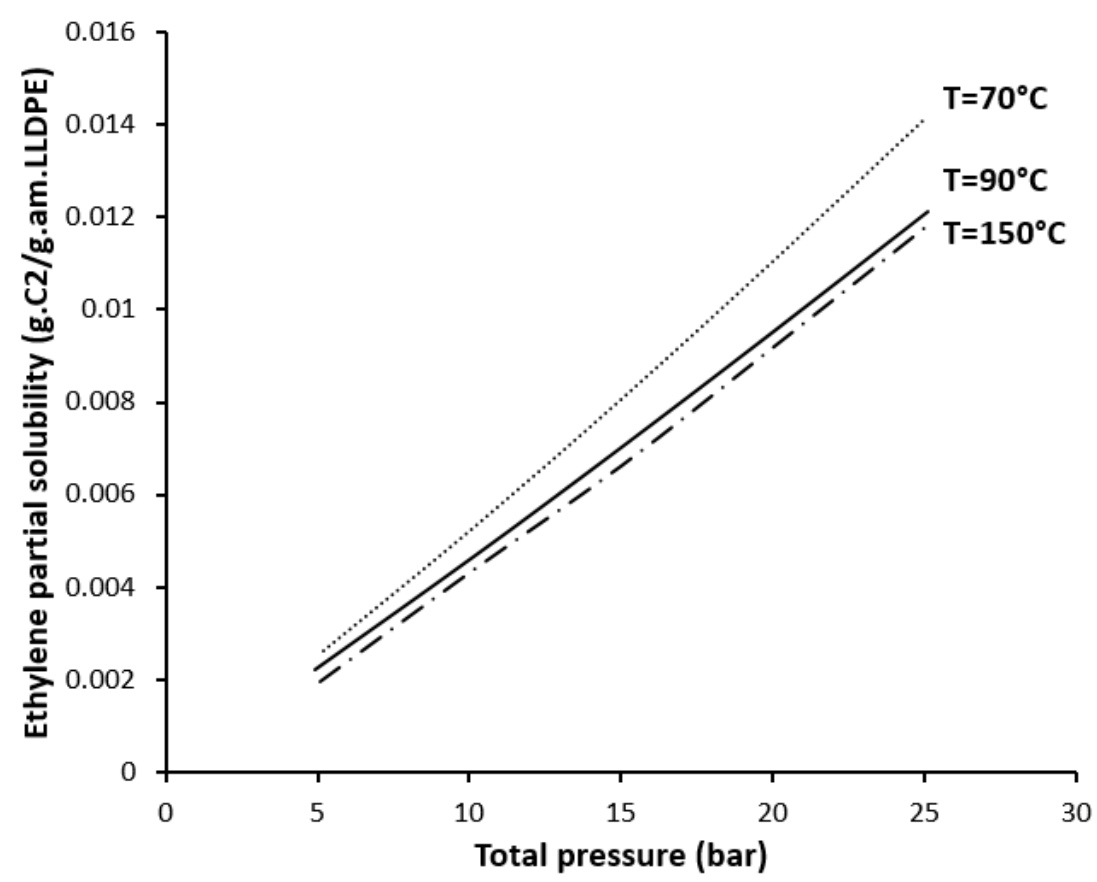

Figure 6. Ethylene partial solubility in ethylene/1-hexene/LLDPE ternary mixture at 70, 90 and $150^{\circ} \mathrm{C}$ calculated from SL EoS. $k_{i j}$ were taken from Table 4.

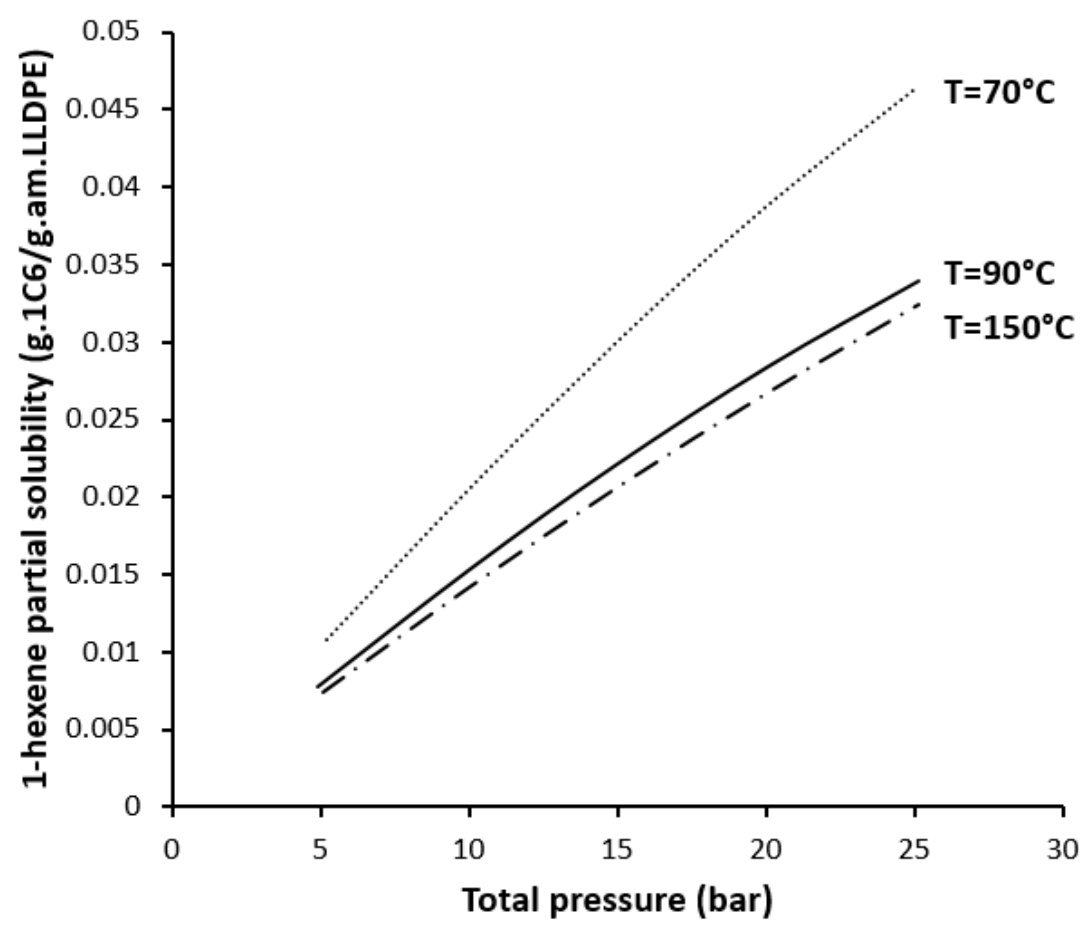


Figure 7. 1-hexene partial solubility in ethylene/1-hexene/LLDPE ternary mixture at 70, 90 and $150^{\circ} \mathrm{C}$ calculated from SL EoS. $k_{i j}$ were taken from Table 4.

We can use these results to study the co- and antisolvent effects of 1-hexene and ethylene in this system. Binary data for ethylene/LLDPE and 1-hexene/LLDPE were taken from Novak et al. $^{13}$ data and then fitted to the binary SL EoS. The correlations of binary $\mathrm{k}_{\mathrm{ij}}$ for ethylene/LLDPE and 1-hexene/LLDPE, with respect to temperature are listed in Table 5. Figures Figure 8 and Figure 9 show the solubility of ethylene and 1-hexene in binary (ethylene/PE and 1-hexene/PE) and ternary (ethylene/1-hexene/PE) systems under the same composition as Novak et al. ${ }^{13}$ (4.3 mol\% 1-hexene and 95.7 mol\% ethylene) for the ternary simulations. The solubilities calculated assuming a binary and/or a ternary system are compared in Figures Figure 8 and Figure 9 for 70 and $90^{\circ} \mathrm{C}$, and the simulations indicate a co-solubility effect which is enhanced at higher temperature. Indeed, it is shown that the partial solubility of ethylene in the ternary system is higher than its binary solubility, meaning that ethylene solubility is enhanced by the addition of 1-hexene to the gas phase (cosolubility effect). On the other hand, it is shown that the ternary partial solubility of 1-hexene is lower than its binary solubility, meaning that ethylene acts as an antisolvent to 1-hexene. It is also shown that the anti-solvent effect of ethylene is higher than the co-solvent effect of 1-hexene.

Table 5. Temperature dependence of $k_{i j}$ for ethylene/LLDPE and 1-hexene/LLDPE binary systems. $\mathrm{T}$ is in ${ }^{\circ} \mathrm{C}$

\begin{tabular}{ll}
\hline System & $k_{i j}$
\end{tabular}

$$
-2.93 \times 10^{-4} T+5.87 \times 10^{-2}
$$

\section{1-hexene/LLDPE}

$$
-8.23 \times 10^{-4} T+8.89 \times 10^{-2}
$$




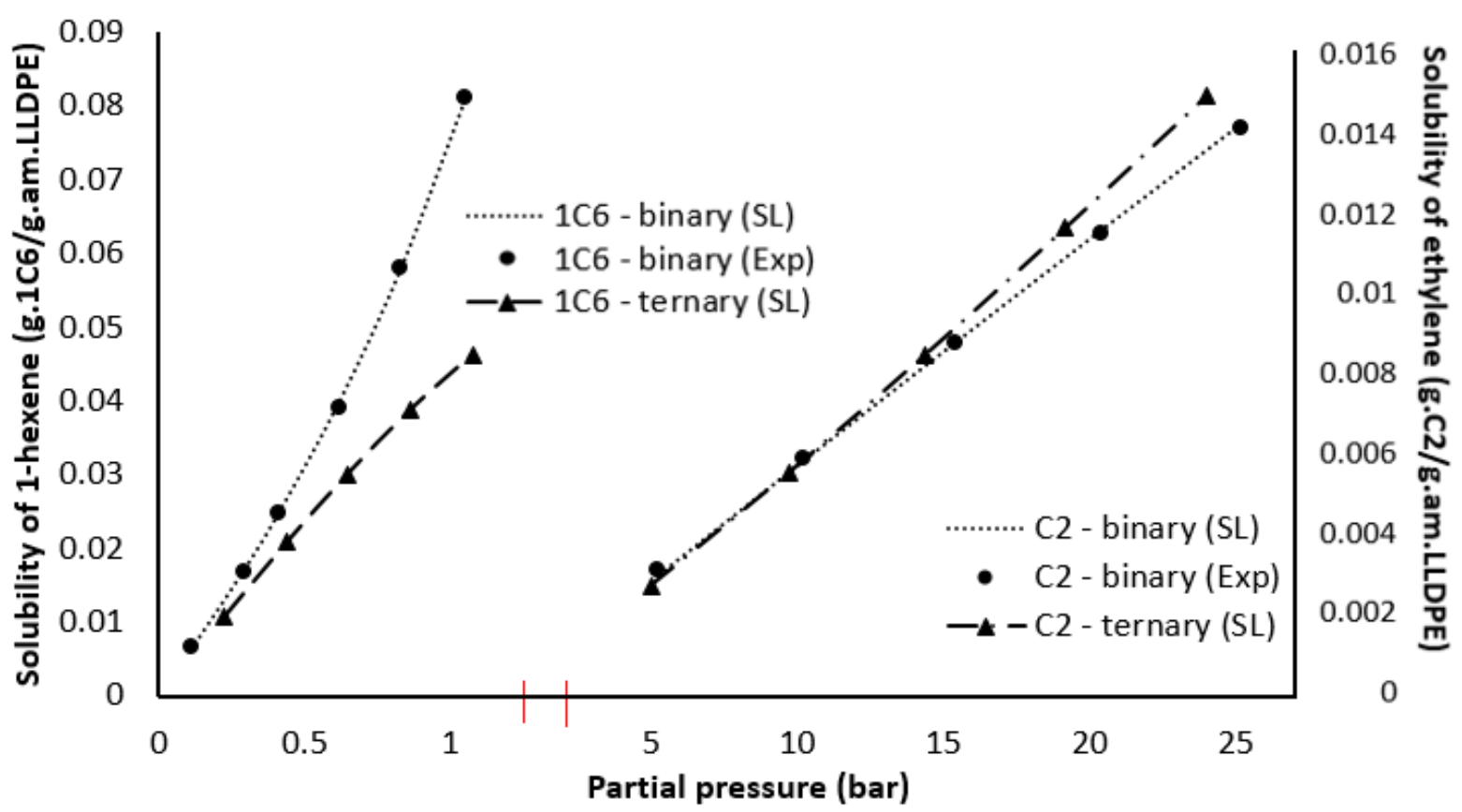

Figure 8. Ethylene and 1-hexene partial solubility in ternary system at $70^{\circ} \mathrm{C}$ with $5 \mathrm{~mol} \% 1$ hexene and $95 \mathrm{~mol} \%$ ethylene and their corresponding partial pressures for each pure component for binary simulations. $k_{i j}$ for ternary system were taken from Table $\mathbf{4}$ and $k_{i j}$ for binary systems were taken from Table 5 . 


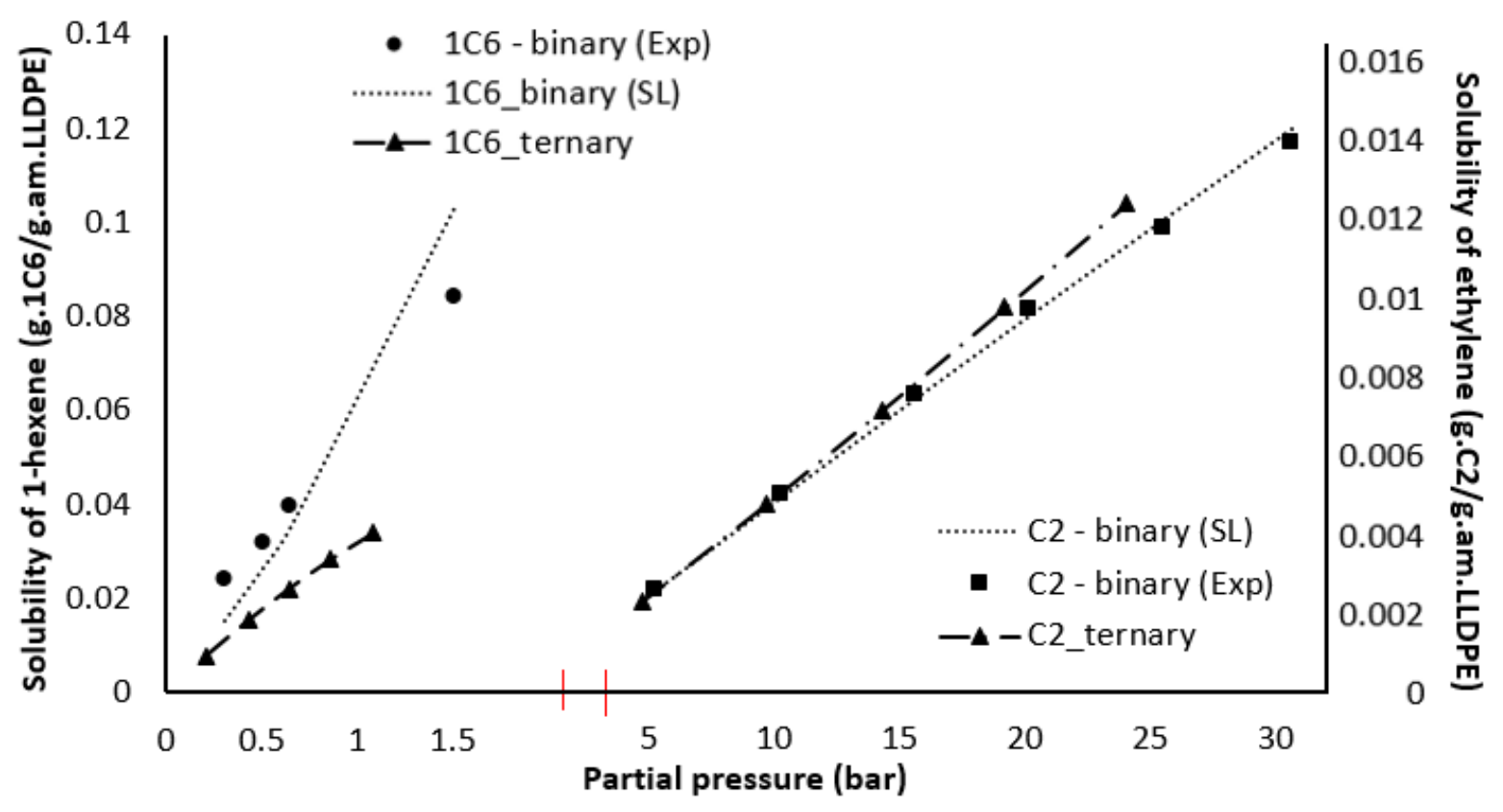

Figure 9. Ethylene and 1-hexene partial solubility in ternary system at $90^{\circ} \mathrm{C}$ with $5 \mathrm{~mol} \% 1$ hexene and $95 \mathrm{~mol} \%$ ethylene and their corresponding partial pressures for each pure component for binary simulations. $k_{i j}$ for ternary system were taken from Table 4 and $k_{i j}$ for binary systems were taken from Table 5 .

The novel approach of SL combined with Peng-Robinson has been validated with the available experimental data for different conditions (i.e. temperature, composition, pressure, polymer type) and show reasonable results. This technique can then be used for the different studied overall solubilities measured with a magnetic suspension balance.

\subsection{Model application to new experimental data}

In general, the solubility of penetrants in the amorphous phase of the polymer depends on the pressure, the temperature, the type of penetrant and PE properties. For the following solubility 
studies, we kept the temperature, PE type and gas phase composition constant; while increasing the total pressure of the injected mixture. Table $\mathbf{6}$ shows the total pressure and the composition of the gas phase mixtures studied here. The overall solubility of these three systems will be measured for a pressure up to 10 bars and a constant temperature of $70^{\circ} \mathrm{C}$. These solubility data will be then correlated using Sanchez-Lacombe combined to PengRobinson to predict the individual solubility data and the interaction parameters.

Table 6. Gas-phase molar composition of the different studied ternary mixtures

\begin{tabular}{ll}
\hline System & Composition \\
\hline & $0<\mathrm{P}_{\mathrm{tot}}<10 \mathrm{bar}$
\end{tabular}

Ethylene / Propane / LLDPE

$$
\begin{gathered}
\mathrm{x}_{\mathrm{C} 2}=0.509 / \mathrm{x}_{\mathrm{C} 3}=0.491 \\
0<\mathrm{P}_{\text {tot }}<10 \text { bar }
\end{gathered}
$$

Ethylene / Isobutane / LLDPE

$$
\begin{gathered}
\mathrm{x}_{\mathrm{C} 2}=0.485 / \mathrm{x}_{\mathrm{iC} 4}=0.515 \\
0<\mathrm{P}_{\text {tot }}<8 \text { bar }
\end{gathered}
$$

Ethylene / 1-butene / LLDPE

$$
\mathrm{x}_{\mathrm{C} 2}=0.617 / \mathrm{x}_{1 \mathrm{C} 4}=0.383
$$

The results of this approach are shown in Figure 10 through Figure 13. The symbols represent experimental values of the total solubility in Figure 10, and the different compressibility factors for the vapor mixtures calculated with Peng-Robinson in FiguresFigure 11-Figure 13. It can be seen from Figure 10 that, as expected, the total solubility increases as the total pressure of the system increases. It is also important to note that the more condensable the penetrant is, the higher the total solubility of the mixture is at a given pressure. Indeed, for a fixed total 
pressure, the total solubility of the mixture in presence of 1-butene is higher than the solubility in presence of isobutane, which is higher than the solubility in presence of propane.

These data points are used to fit the $k_{i j}$ from SL EoS for the different mixtures, the values of which are shown in Table 7. Indeed, when one has only global solubilities, identifying these interaction parameters is crucial in order to have the partial solubilities of each component in the mixture. These parameters are also useful to predict the solubility at different pressures. In order to do so, the approach discussed above was used to fit both global solubility from SL EoS to experiments and compressibility factor from SL EoS to Peng-Robinson EoS. Note that the model fits the data well, with the difference between the model and the experiments in Figure 10 being on the order of $1-4 \%$, indicating that we can have confidence in these values for the pressure and temperature used in the experiments. Figures Figure 11-Figure 13 show that the calculated compressibility factors from SL EoS are in good agreement with the ones calculated with Peng-Robinson EoS, with a maximum difference of $0.8 \%$. It should be pointed that this set of interaction parameters are only valid at temperature equal to $70^{\circ} \mathrm{C}$.

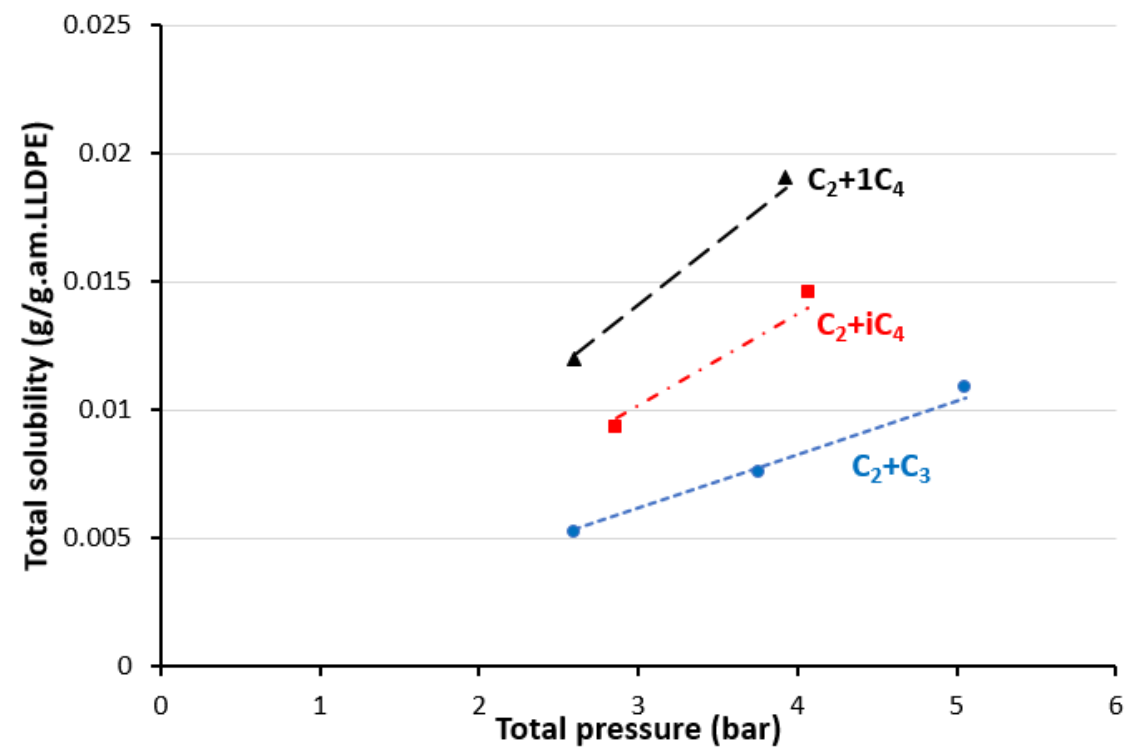


Figure 10. Total solubility of ethylene/penetrant mixture in LLDPE in presence of different penetrants at $70^{\circ} \mathrm{C}$. Points represent experimental values (average of 2 or 3 runs) and the lines represent the predictions of the SL EoS with the fitted parameters. $k_{\mathrm{ij}}$ are defined in

\section{Table 7.}

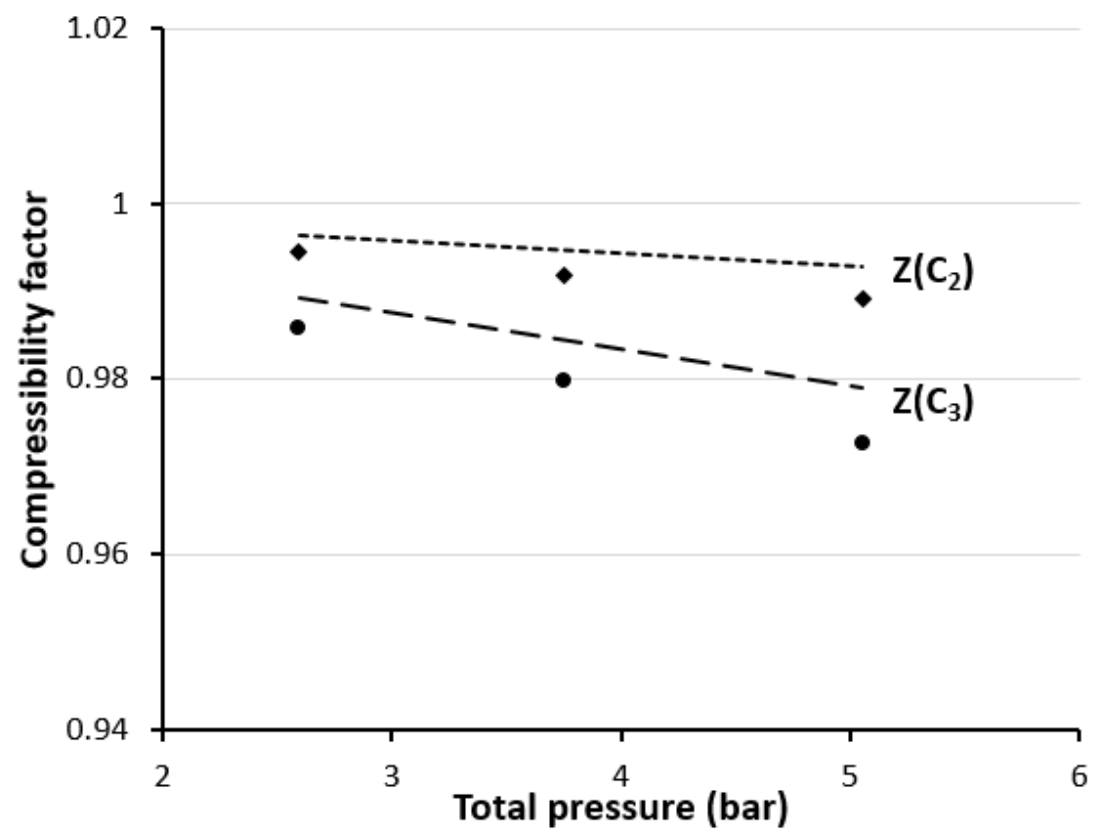

Figure 11. Compressibility factor of ethylene $\left(C_{2}\right)$ and propane $\left(C_{3}\right)$ in $C_{2} / C_{3} / L L D P E$ mixture. Points represent compressibility values calculated with Peng-Robinson and the lines represent the predictions of the compressibility factor from the ternary SL EoS. 


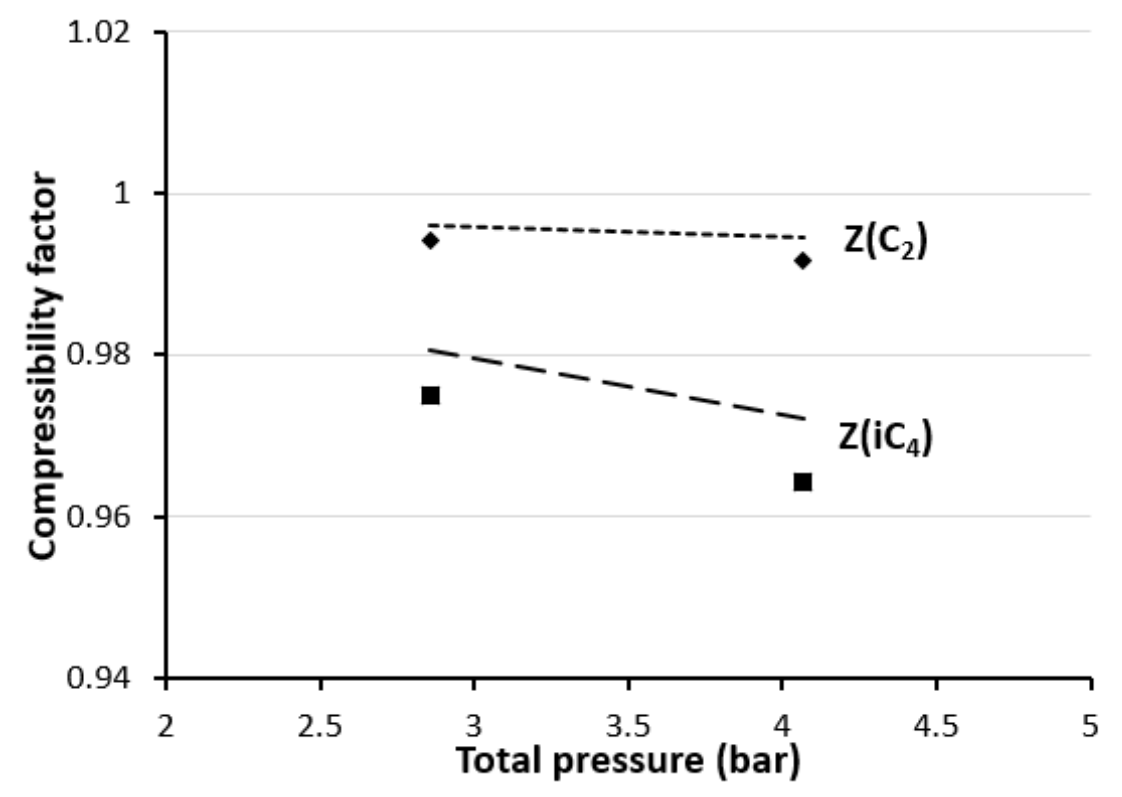

Figure 12. Compressibility factor of ethylene $\left(\mathrm{C}_{2}\right)$ and isobutane $\left(\mathrm{iC}_{4}\right)$ in $\mathrm{C}_{2} / \mathrm{iC}_{4} / \mathrm{LLDPE}$ mixture. Points represent compressibility values calculated with Peng-Robinson and the lines represent the predictions of the compressibility factor from the ternary SL EoS.

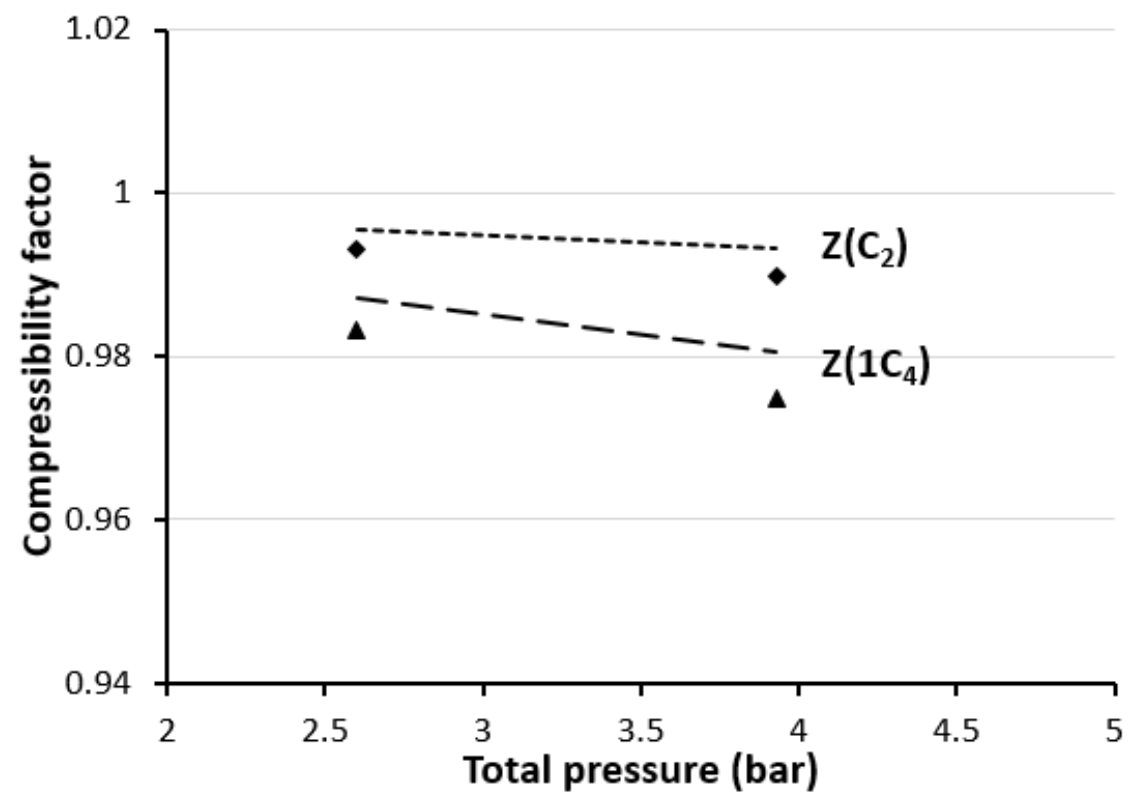


Figure 13. Compressibility factor of ethylene $\left(\mathrm{C}_{2}\right)$ and 1-butene $\left(1 \mathrm{C}_{4}\right)$ in $\mathrm{C}_{2} / 1 \mathrm{C}_{4} / \mathrm{LLDPE}$ mixture. Points represent compressibility values calculated with Peng-Robinson and the lines represent the predictions of the compressibility factor from the ternary SL EoS

Table 7. Identified ternary interaction parameters by fitting experimental solubility data to SL EoS for different systems and temperatures

$$
T\left({ }^{\circ} \mathbf{C}\right)
$$$$
\text { Ethylene/Isobutane/ }
$$

Ethylene/1-butene/

Ethylene/Propane/
LLDPE
LLDPE
LLDPE

$$
k_{13}=-0.06856
$$

$$
k_{13}=-0.09495
$$

$$
k_{13}=-0.03329
$$

70

$$
k_{23}=0.04839 \quad k_{23}=0.04618 \quad k_{23}=0.03905
$$

Once the $k_{i j}$ identified by this new approach, we can calculate the partial solubility of each component in the mixture. Figures Figure 14, Figure 15 and Figure 16 show the global and partial solubility of each component of the mixture in the amorphous phase of LLDPE, in presence of different penetrants; propane, isobutane and 1-butene, respectively. It is shown, as expected for the considered molar fraction that the partial solubility of ethylene is lower than the partial solubility of the heavier components (i.e. propane, isobutane, 1-butene). 


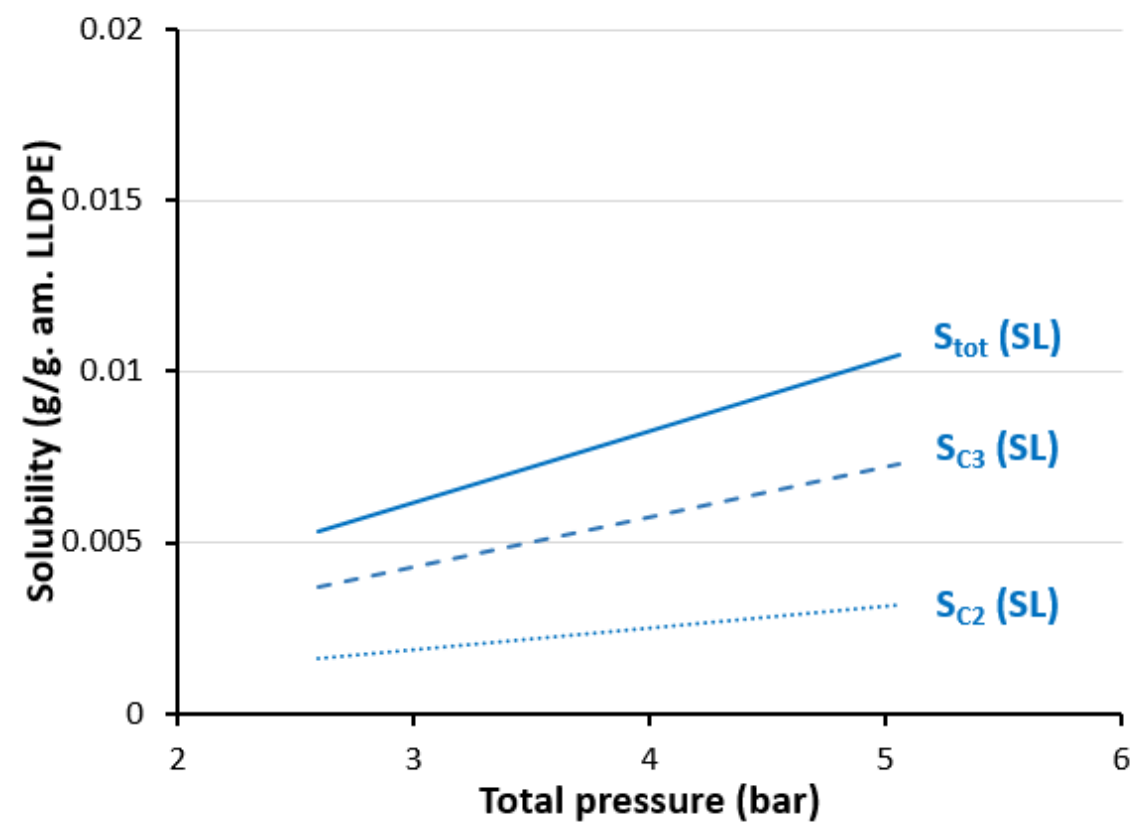

Figure 14. Total solubility $\mathrm{S}_{\mathrm{tot}}(\mathrm{SL})$, partial solubility of ethylene $\mathrm{S}_{\mathrm{C} 2}$ (SL) and partial solubility of propane $\mathrm{S}_{\mathrm{C} 3}$ (SL) in LLDPE at $70^{\circ} \mathrm{C}$ from SL-PR method (ternary system $\mathrm{C}_{2} / \mathrm{C}_{3} /$ LLDPE). $k_{i j}$ are defined in Table 7.

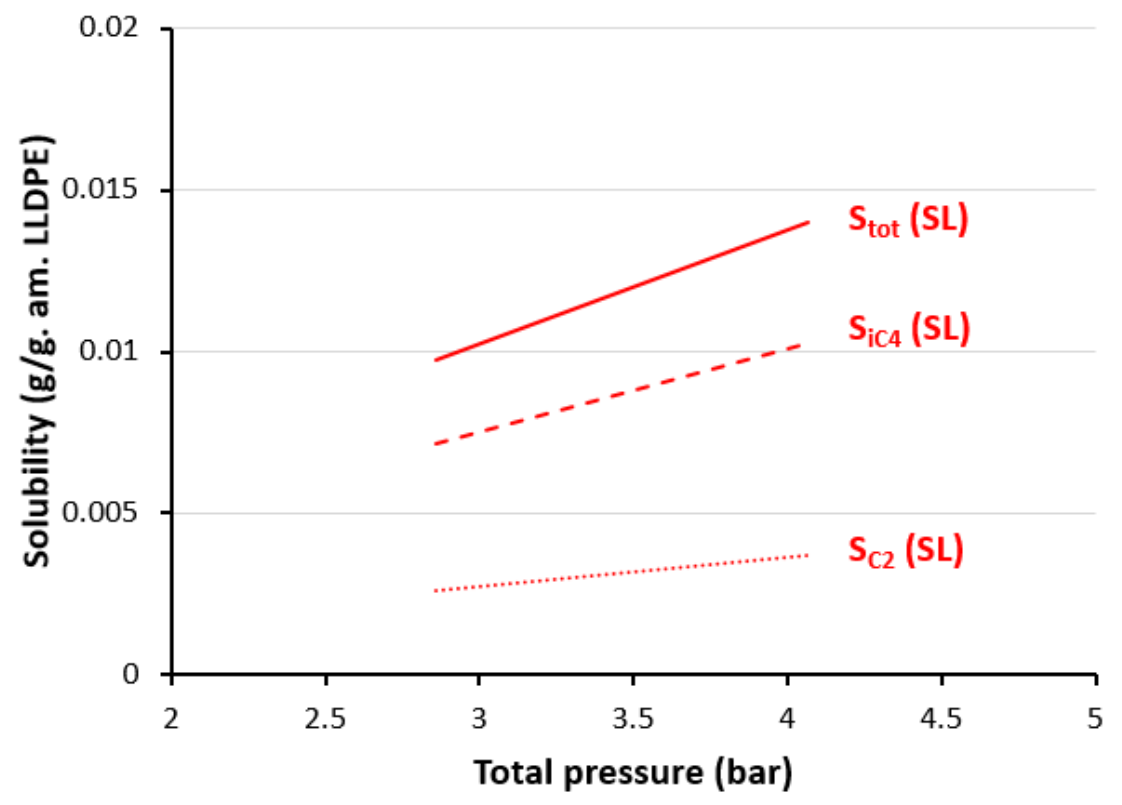


Figure 15. Total solubility $\mathrm{S}_{\mathrm{tot}}(\mathrm{SL})$, partial solubility of ethylene $\mathrm{S}_{\mathrm{C} 2}$ (SL) and partial solubility of isobutane $\mathrm{S}_{\mathrm{iC} 4}(\mathrm{SL})$ in LLDPE at $70^{\circ} \mathrm{C}$ from $\mathrm{SL}$ EoS (ternary system $\left.\mathrm{C}_{2} / \mathrm{iC}_{4} / \mathrm{LLDPE}\right) . k_{i j}$ are defined in Table 7.

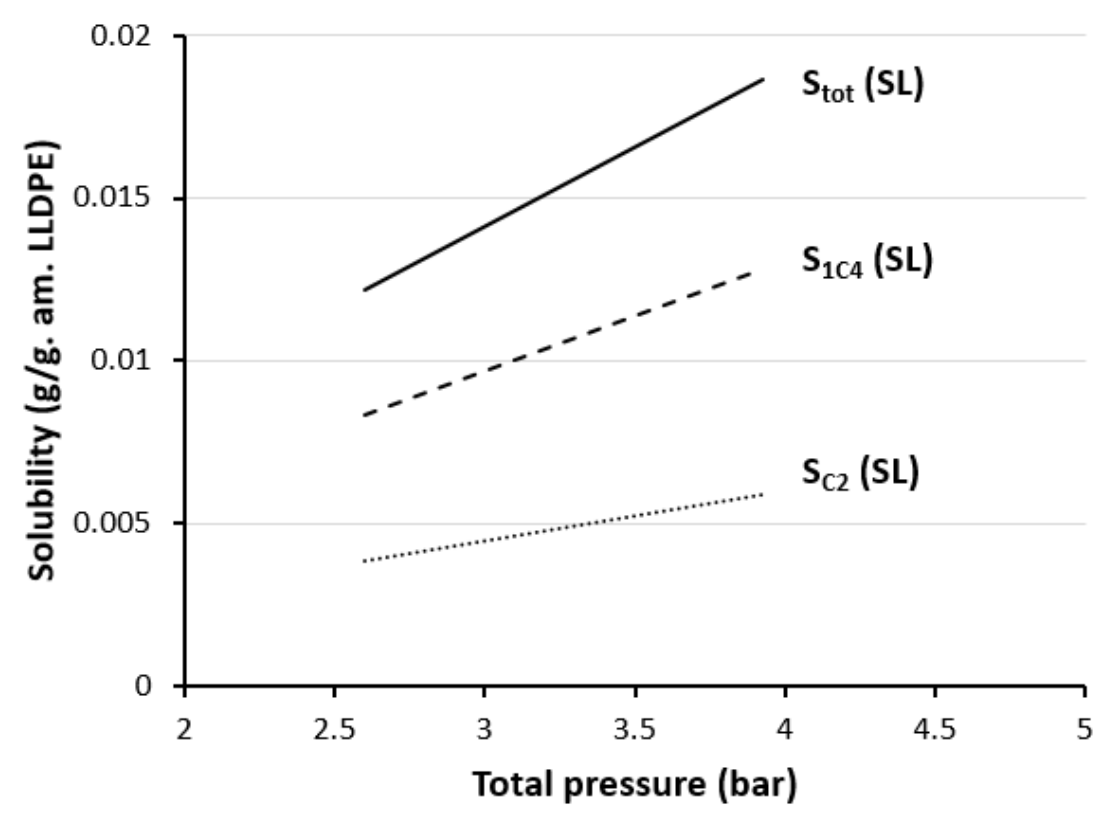

Figure 16. Total solubility $\mathrm{S}_{\mathrm{tot}}(\mathrm{SL})$, partial solubility of ethylene $\mathrm{S}_{\mathrm{C} 2}$ (SL) and partial solubility of 1-butene $\mathrm{S}_{1 \mathrm{C} 4}(\mathrm{SL})$ in LLDPE from SL EoS (ternary system $\left.\mathrm{C}_{2} / 1 \mathrm{C}_{4} / \mathrm{LLDPE}\right) . k_{i j}$ are defined in Table 7.

Figure 17 shows the experimental solubility of ethylene in the binary system ethylene/LLDPE and the ternary solubility of ethylene in presence of propane, isobutane and 1-butene in LLDPE. It shows that the ternary solubility of ethylene is higher than its corresponding binary solubility due to the co-solubility effect. Indeed, adding heavier components will increase the solubility of ethylene and vice-versa. Besides, it shows that the heavier the penetrant, the higher the partial solubility of ethylene in the amorphous phase of LLDPE. Note that the molar fractions were not exactly the same for all the components (Table 6). However, if we consider 1-butene for instance, its molar fraction was lower than isobutane and propane 
$\left(\mathrm{X}_{1 \mathrm{C} 4}=0.383, \mathrm{X}_{\mathrm{iC} 4}=0.515\right.$ and $\left.\mathrm{X}_{\mathrm{C} 3}=0.491\right)$. Even with a lower fraction of 1-butene, the cosolubility effect was higher than isobutene as well as propane.

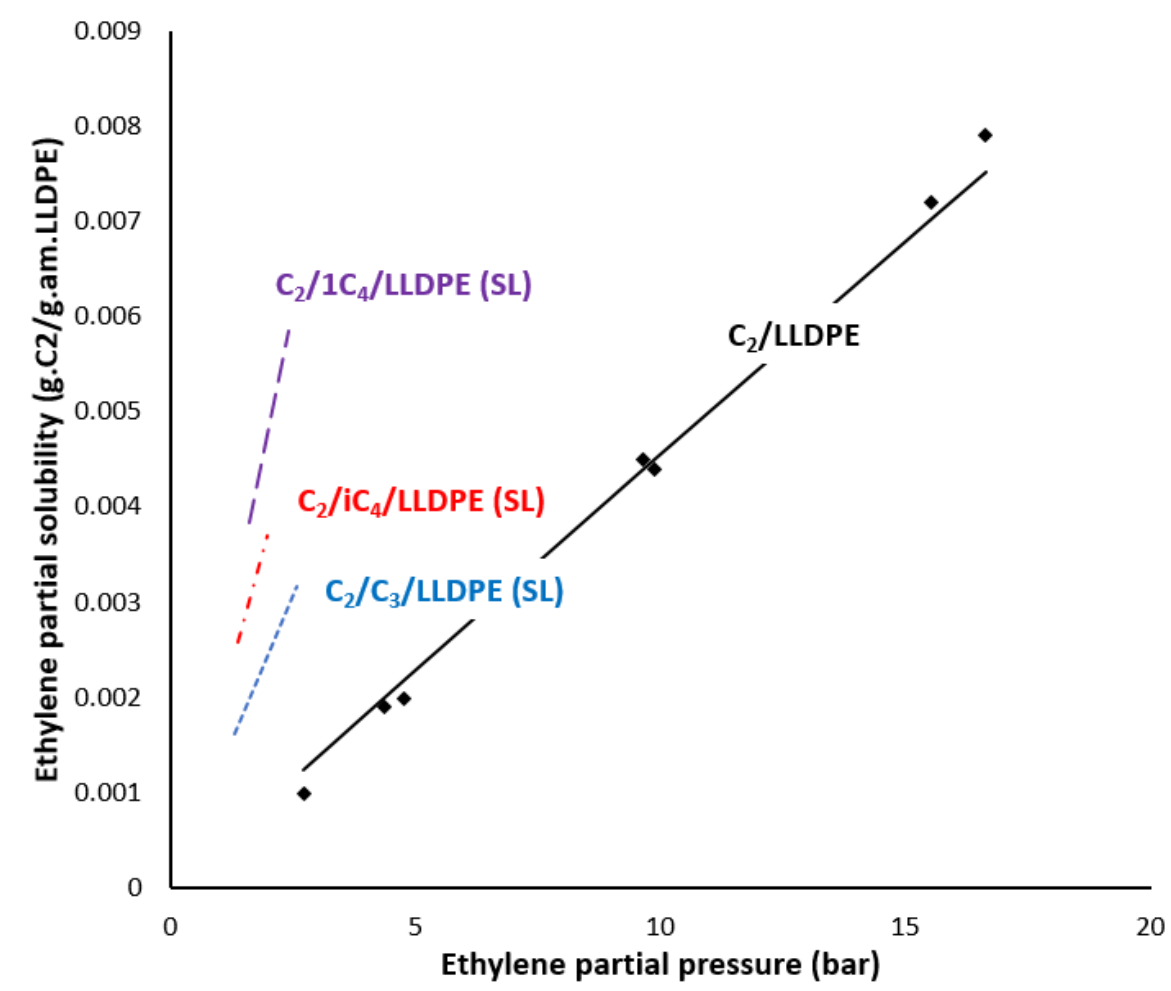

Figure 17. Partial ternary solubility of ethylene from SL EoS in presence of $\mathrm{C}_{3}, \mathrm{iC}_{4}$ and $1 \mathrm{C}_{4}$ with the molar fractions: $\mathrm{X}_{1 \mathrm{C} 4}=0.383, \mathrm{X}_{\mathrm{iC} 4}=0.515$ and $\mathrm{X}_{\mathrm{C} 3}=0.491 ; k_{i j}$ for ternary systems are defined in Table 7. Comparison to binary solubility of C2/LLDPE, where points represent the experimental solubility and the line represents the solubility fitted from SL EoS. with $k_{i j}$ defined in Table 8 


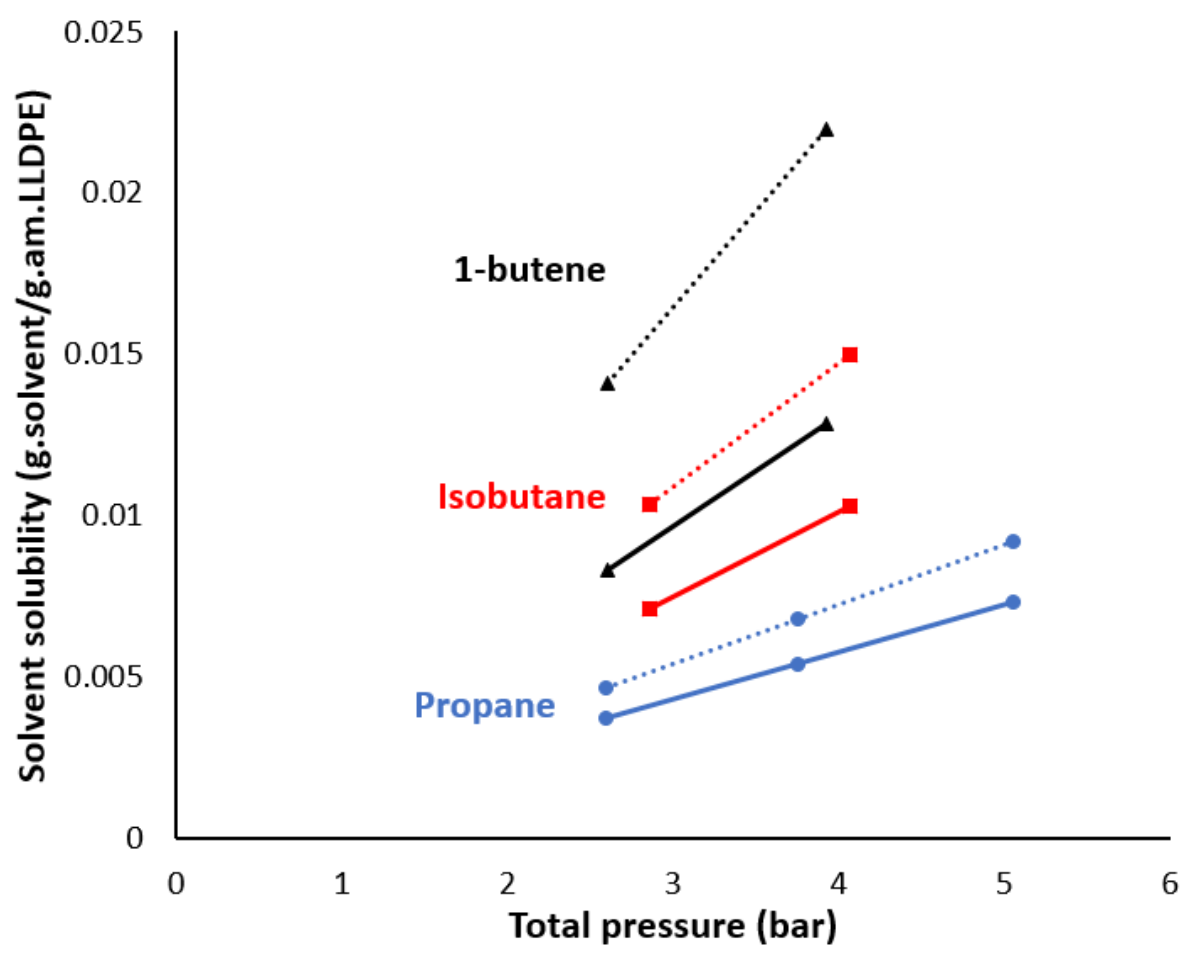

Figure 18 shows the solubility of propane, isobutane and 1-butene in binary (diluent/PE) and ternary (ethylene/diluent/PE) systems. The same compositions as in Table 6 were used for the ternary simulations and their corresponding partial pressures for each pure component were used for the binary simulation. This figure shows the anti-solvent behavior of ethylene. Indeed, adding ethylene to the gas phase composition decreases the solubility of ICAs, with respect to binary solubility. Ethylene acts therefore as an anti-solvent to ICA by decreasing ICA partial solubility. Besides, we can see that ethylene anti-solvent effect is higher (about $20 \%$ ) for isobutane than for propane (note that they were added at almost the same fraction $\mathrm{X}_{\mathrm{iC} 4}=0.515$ and $\left.\mathrm{X}_{\mathrm{C} 3}=0.491\right)$. 


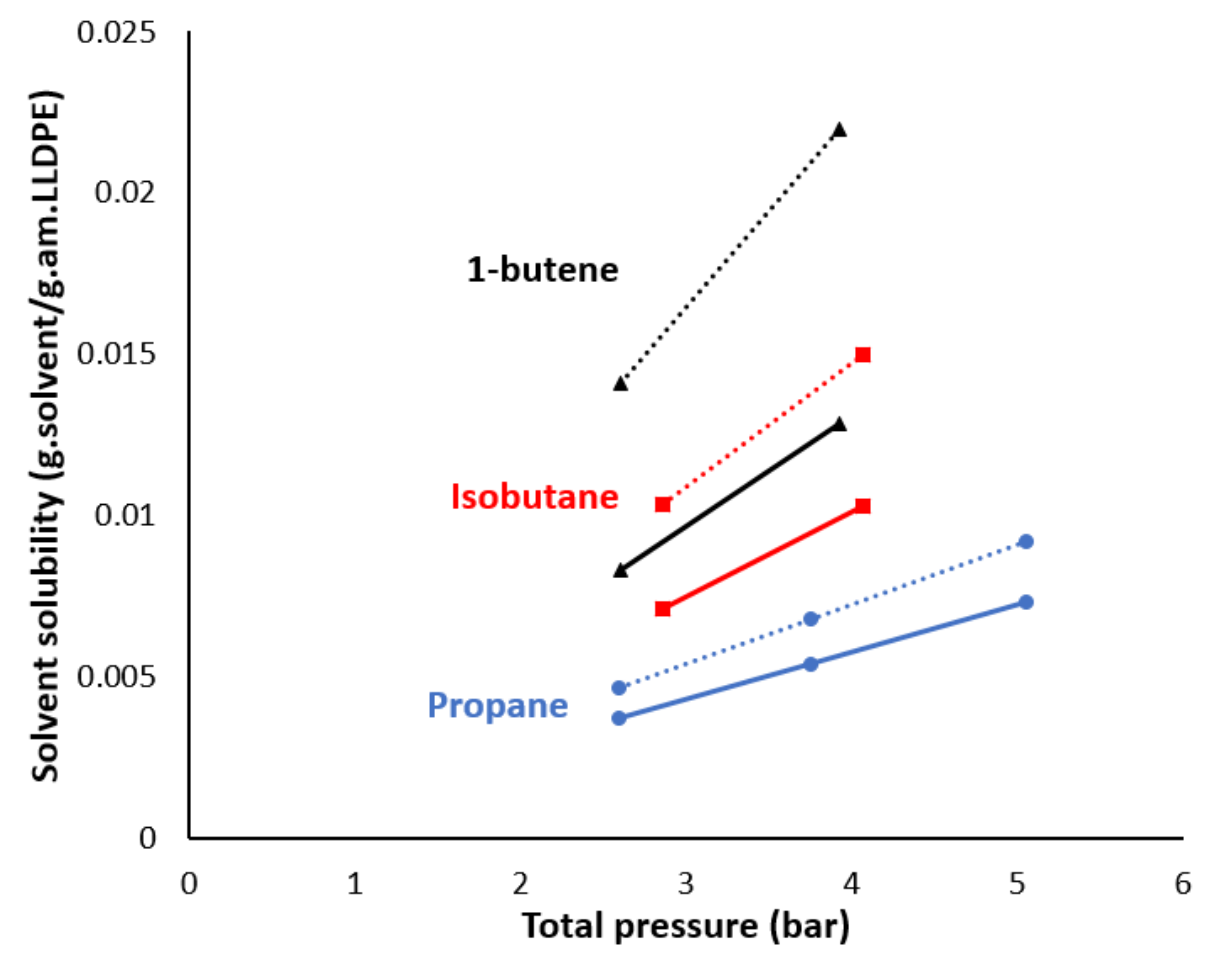

Figure 18. Solubility of propane, isobutane and 1-butene in binary (diluent/LLDPE) and ternary (ethylene/diluent/LLDPE) systems using SL EoS. $k_{i j}$ for ternary systems are defined in Table 7. $k_{i j}$ for binary systems are defined in Table 8 . The lines represent diluent partial solubility in ternary systems and the dotted lines represent diluent solubility in binary systems.

Table 8. Binary interaction parameters at $\mathrm{T}=70^{\circ} \mathrm{C}$ used in this work

\begin{tabular}{lcc}
\hline System & Binary $\boldsymbol{k}_{i j}$ & Ref \\
\hline Ethylene/LLDPE & 0.0546 & Our work \\
\hline Propane/LLDPE & 0.023 & 10 \\
\hline
\end{tabular}




\section{Conclusion}

The overall equilibrium solubility of ethylene/propane/LLDPE, ethylene/isobutane/LLDPE and ethylene/1-butene/LLDPE were determined gravimetrically at $70^{\circ} \mathrm{C}$ in the pressure range 0-10 bar. The measured solubilities were evaluated in gram of the mixture per gram of amorphous PE. The observed trends were theoretically interpreted because no available data can be found in the literature for these studied systems. Indeed, the results showed, as expected, an anti-solvent behavior of ethylene and a co-solvent behavior of penetrant. Besides, the more condensable the penetrant, the higher will be these effects.

The measured solubilities were then fitted to Sanchez-Lacombe equation of state, in order to identify interactions parameters $k_{i j}$. In this work, a novel approach consisting of implementing Peng-Robinson to SL EoS (i.e. SL-PR) has been used in order to predict the interactions parameters needed for SL EoS. Indeed, having the compressibility factor as input data is crucial when having only global solubilities since we can therefore have an additional data for the fitting. Besides, this will be important when extending SL EoS to quaternary systems, since we will have three interaction parameters that needs to be identified from SL EoS. Good agreement is observed between experimental overall solubility and SL EoS combined to Peng-Robinson, with a difference of $1-4 \%$ for overall solubilities and a maximum of $0.8 \%$ for the compressibility factor.

\section{Acknowledgements}

ABM, NSO and TFLM gratefully acknowledge the support of the Agence Nationale de la Recherche (Projet ANR- 16-CE93-0001 - Thermopoly). The authors would also like to acknowledge Ms. Rita Ferreira Alves for her helpful discussions on the model development. 


\section{References}

1. Polyolefin Microstructural Modeling. in Polyolefin Reaction Engineering 187-269 (WileyVCH Verlag GmbH \& Co. KGaA, 2012). doi:10.1002/9783527646944.ch6.

2. McKenna, T. F. L. Condensed Mode Cooling of Ethylene Polymerization in Fluidized Bed Reactors. Macromol. React. Eng. 13, 1800026 (2019).

3. III, J. M. J., Jones, R. L., Jones, T. M. \& Beret, S. Method for fluidized bed polymerization. (1986).

4. Iii, J. M. J., Jones, R. L., Jones, T. M. \& Beret, S. A method for controlling the temperature of a fluidized bed especially a process for producing polymers. (1987).

5. Alizadeh, A. \& McKenna, T. F. L. Condensed Mode Cooling in Ethylene Polymerisation: Droplet Evaporation. Macromol. Symp. 333, 242-247 (2013).

6. Namkajorn, M., Alizadeh, A., Somsook, E. \& McKenna, T. F. L. Condensed-Mode Cooling for Ethylene Polymerization: The Influence of Inert Condensing Agent on the Polymerization Rate. Macromol. Chem. Phys. 215, 873-878 (2014).

7. Alizadeh, A., Namkajorn, M., Somsook, E. \& McKenna, T. F. L. Condensed Mode Cooling for Ethylene Polymerization: Part I. The Effect of Different Induced Condensing Agents on Polymerization Rate. Macromolecular Chemistry and Physics 216, 903-913 (2015).

8. Namkajorn, M., Alizadeh, A., Romano, D., Rastogi, S. \& McKenna, T. F. L. Condensed Mode Cooling for Ethylene Polymerization: Part III. The Impact of Induced Condensing Agents on Particle Morphology and Polymer Properties. Macromolecular Chemistry and Physics 217, 1521-1528 (2016). 
9. Banaszak, B. J. et al. Ethylene and 1-Hexene Sorption in LLDPE under Typical Gas Phase Reactor Conditions: A Priori Simulation and Modeling for Prediction of Experimental Observations. Macromolecules 37, 9139-9150 (2004).

10. Alves, R., Bashir, M. A. \& McKenna, T. F. L. Modeling Condensed Mode Cooling for Ethylene Polymerization: Part II. Impact of Induced Condensing Agents on Ethylene Polymerization in an FBR Operating in Super-Dry Mode. Ind. Eng. Chem. Res. 56, 1358213593 (2017).

11. Yao, W., Hu, X. \& Yang, Y. Modeling the solubility of ternary mixtures of ethylene,isopentane,n-hexane in semicrystalline polyethylene. J. Appl. Polym. Sci. 104, 3654-3662 (2007).

12. McKenna, T. F. Solubility and crystallinity data for ethylene/polyethylene systems. European Polymer Journal 34, 1255-1260 (1998).

13. Novak, A. et al. Ethylene and 1-hexene sorption in LLDPE under typical gas-phase reactor conditions: Experiments. J. Appl. Polym. Sci. 100, 1124-1136 (2006).

14. Chmelař, J., Haškovcová, K., Podivinská, M. \& Kosek, J. Equilibrium Sorption of Propane and 1-Hexene in Polyethylene: Experiments and Perturbed-Chain Statistical Associating Fluid Theory Simulations. Ind. Eng. Chem. Res. 56, 6820-6826 (2017).

15. Yao, W., Hu, X. \& Yang, Y. Modeling solubility of gases in semicrystalline polyethylene. J. Appl. Polym. Sci. 103, 1737-1744 (2007).

16. Moore, S. J. \& Wanke, S. E. Solubility of ethylene, 1-butene and 1-hexene in polyethylenes. Chemical Engineering Science 56, 4121-4129 (2001). 
17. Savatsky, B. J., Moebus, J. A. \& Greenhalgh, Brian. R. Parameterization of Models for Vapor Solubility in Semicrystalline Polyethylene. Macromol. React. Eng. 13, 1900003 (2019).

18. Kanellopoulos, V., Mouratides, D., Pladis, P. \& Kiparissides, C. Prediction of Solubility of $\alpha$-Olefins in Polyolefins Using a Combined Equation of State Molecular Dynamics Approach. Ind. Eng. Chem. Res. 45, 5870-5878 (2006).

19. Yoon, J.-S., Yoo, H.-S. \& Kang, K.-S. Solubility of $\alpha$-olefins in linear low density polyethylenes. European Polymer Journal 32, 1333-1336 (1996).

20. Moebus, J. A. \& Greenhalgh, B. R. Modeling Vapor Solubility in Semicrystalline Polyethylene. Macromol. React. Eng. 12, 1700072 (2018).

21. Bashir, M. A., Al-haj Ali, M., Kanellopoulos, V. \& Seppälä, J. Modelling of multicomponent olefins solubility in polyolefins using Sanchez-Lacombe equation of state. Fluid Phase Equilibria 358, 83-90 (2013).

22. Nath, S. K., Banaszak, B. J. \& de Pablo, J. J. Simulation of Ternary Mixtures of Ethylene, 1Hexene, and Polyethylene. Macromolecules 34, 7841-7848 (2001).

23. Sun, J. et al. Solubility measurement of hydrogen, ethylene, and 1-hexene in polyethylene films through an intelligent gravimetric analyzer. J. Appl. Polym. Sci. 134, (2017).

24. Bashir, M. A., Monteil, V., Kanellopoulos, V., Ali, M. A.-H. \& McKenna, T. Partial Molar Volumes and Thermal Expansion Coefficients as an Explanation for Co-Solvent Effect of 
Penetrants in Multicomponent Polymer Mixtures. Macromol. Chem. Phys. 216, 21292140 (2015).

25. Gross, J. \& Sadowski, G. Modeling Polymer Systems Using the Perturbed-Chain Statistical Associating Fluid Theory Equation of State. Ind. Eng. Chem. Res. 41, 1084-1093 (2002).

26. Krallis, A. \& Kanellopoulos, V. Application of Sanchez-Lacombe and Perturbed-Chain Statistical Associating Fluid Theory Equation of State Models in Catalytic Olefins (Co)polymerization Industrial Applications. Ind. Eng. Chem. Res. 52, 9060-9068 (2013).

27. Sanchez, I. C. \& Lacombe, R. H. An elementary molecular theory of classical fluids. Pure fluids. J. Phys. Chem. 80, 2352-2362 (1976).

28. Alizadeh, A. et al. Modeling Condensed Mode Operation for Ethylene Polymerization: Part I. Thermodynamics of Sorption. Ind. Eng. Chem. Res. 56, 1168-1185 (2017).

29. Alizadeh, A. Study of sorption, heat and mass transfer during condensed mode operation of gas phase ethylene polymerization on supported catalyst. (Departement of Chemical Engineering, Queen's University, 2014).

30. Chmelař, J. et al. Equilibrium sorption of ethylene in polyethylene: Experimental study and PC-SAFT simulations. Polymer 59, 270-277 (2015).

31. Cancelas, A. J. et al. Solubility and Diffusivity of Propylene, Ethylene, and PropyleneEthylene Mixtures in Polypropylene. Macromol. Chem. Phys. 219, 1700565 (2018).

32. Kröner, T. \& Bartke, M. Sorption of Olefins in High Impact Polypropylene - Experimental Determination and Mass Transport Modeling. Macromolecular Reaction Engineering 7, 453-462 (2013). 
33. Bashir, M. A., Ali, M. A., Kanellopoulos, V. \& Seppälä, J. Combined EoS and elastic constraints models to predict thermodynamic properties for systems involving semicrystalline polyolefins. Fluid Phase Equilibria 388, 107-117 (2015).

34. Peng, D.-Y. \& Robinson, D. B. A New Two-Constant Equation of State. Ind. Eng. Chem. Fund. 15, 59-64 (1976).

35. Poling, B., Prausnitz, J. \& O'Connell, J. The Properties of Gases and Liquids. (2000).

36. Lin, H. \& Duan, Y.-Y. Empirical correction to the Peng-Robinson equation of state for the saturated region. Fluid Phase Equilibria 233, 194-203 (2005).

37. Ambrose, D. Vapour-Liquid Critical Properties. (1979).

38. Mirzaei, A., Kiashemshaki, A. \& Emami, M. Fluidized Bed Polyethylene Reactor Modeling in Condensed Mode Operation. Macromol. Symp. 259, 135-144 (2007).

39. Chmelar, J. et al. Softening of polyethylene powders at reactor conditions. Chemical Engineering Journal 228, 907-916 (2013). 